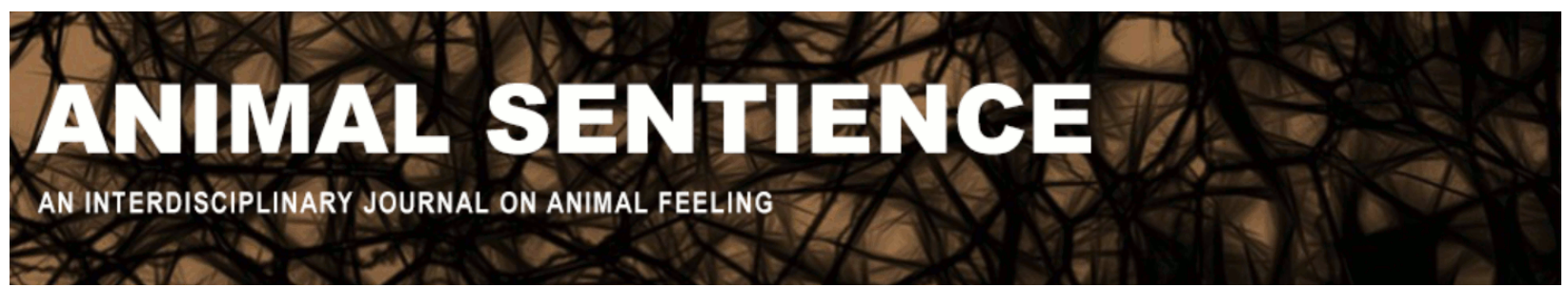

Klein, Colin and Barron, Andrew B. (2016) Insects have the capacity for subjective experience. Animal Sentience 9(1)

DOI: $10.51291 / 2377-7478.1113$

Date of submission: 2016-06-25

Date of acceptance: 2016-07-11

(c)

This article has appeared in the journal Animal

Sentience, a peer-reviewed journal on animal

cognition and feeling. It has been made open access,

free for all, by WellBeing International and deposited

in the WBI Studies Repository. For more information,

please contact

wbisr-info@wellbeingintl.org.

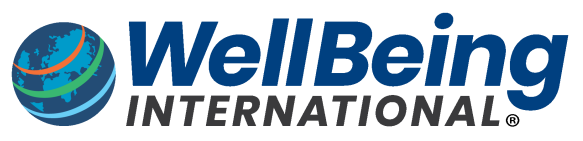

SOLUTIONS FOR PEOPLE, ANIMALS AND ENVIRONMENT 
Call for Commentary: Animal Sentience publishes Open Peer Commentary on all accepted target articles. Target articles are peer-reviewed. Commentaries are editorially reviewed. There are submitted commentaries as well as invited commentaries. Commentaries appear as soon as they have been revised and accepted. Target article authors may respond to their commentaries individually or in a joint response to multiple commentaries.

Instructions: http://animalstudiesrepository.org/animsent/guidelines.html

\title{
Insects have the capacity for subjective experience
}

\author{
Colin Klein ${ }^{*}$ \& Andrew B. Barron ${ }^{2 *}$ \\ ${ }^{1}$ Department of Philosophy, Macquarie University \\ 2Department of Biological Sciences, Macquarie University \\ *equal authorship contribution
}

\begin{abstract}
To what degree are non-human animals conscious? We propose that the most meaningful way to approach this question is from the perspective of functional neurobiology. Here we focus on subjective experience, which is a basic awareness of the world without further reflection on that awareness. This is considered the most basic form of consciousness. Tellingly, this capacity is supported by the integrated midbrain and basal ganglia structures, which are among the oldest and most highly conserved brain systems in vertebrates. A reasonable inference is that the capacity for subjective experience is both widespread and evolutionarily old within the vertebrate lineage. We argue that the insect brain supports functions analogous to those of the vertebrate midbrain and hence that insects may also have a capacity for subjective experience. We discuss the features of neural systems which can and cannot be expected to support this capacity as well as the relationship between our arguments based on neurobiological mechanism and our approach to the "hard problem" of conscious experience.
\end{abstract}

Keywords: subjective experience, primary consciousness, vertebrate midbrain, superior colliculus, invertebrate, insect

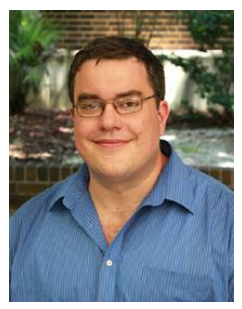

Colin Klein is Senior Lecturer in the Department of Philosophy at Macquarie University. He works on philosophy of neuroscience with a side interest in the perception of pain and other homeostatically relevant states. In 2014 he received an ARC Future Fellowship to look at interventionist approaches to cognitive neuroscience. http://www.colinklein.org

Andrew B. Barron is Associate Professor in the Department of Biological Sciences at Macquarie University. With his team at Macquarie, he is exploring the neurobiology of major behavioural systems such as memory, goal-directed behaviour and stress from a comparative and evolutionary perspective. In 2015 he was awarded an ARC Future Fellowship to develop a computational model of the honey bee brain. http://bio.mq.edu.au/research/groups/cognitiveneuroethology/dr-andrew-barron/

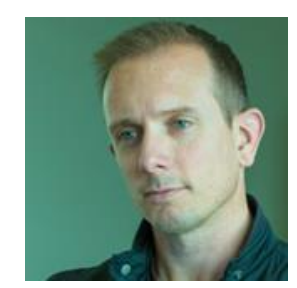




\section{Introduction}

What follows is a synopsis of our argument in Barron \& Klein (2016). Our intention here is both to summarize our arguments from comparative functional neurobiology that insects have subjective experience as well as to expand upon and clarify some points from our previous article. Here we provide some further discussion of why we believe the insect brain is capable of subjective experience and of the features of nervous system organization which do and do not have this capacity. We conclude with reflections on the relationship between our structural arguments and the so-called "hard problem of consciousness" (Chalmers, 1996).

\section{Consciousness and Subjective Experience}

Consciousness is a complex, multifaceted phenomenon (Bayne, Hohwy, \& Owen, 2016). Terminology to describe consciousness has proliferated more quickly than our understanding of the phenomenon. Most authors, however, mark off a very basic sense of "conscious" that refers to the basic capacity to have subjective experience (Morin, 2006). In Nagel's (1974) familiar term of art, there is "something it is like" to be an organism with subjective experience. Organisms capable of subjective experience do more than merely react: they have a perspective on the world with a unique phenomenological feel.

We distinguish this minimal level of consciousness from more demanding conscious relations. We think it is possible to have subjective experience without higher-order thoughts (Edelman, 2003; Rosenthal, 2005), self-awareness of oneself as a subject (Christoff, Cosmelli, Legrand, \& Thompson, 2011; Morin, 2006), or reportable access to one's own phenomenal states (Block, 1995). We think, in short, that it is possible to simply be aware, with no further reflection.

Such a distinction is, of course, philosophically contentious. Some believe that subjective experience requires heavier capacities for self-reflection. We justify adopting this distinction in three ways. First, we think that this is the modal position among philosophers and consciousness scientists. Second, adopting such a distinction corrects for potential anthropocentric bias. Third, the distinction alone does not secure our conclusion. We argue that insects have the capacity for subjective experience. Even those who think that sentience without self-reflection is possible are wary of including insects on our side of the line. Hence work remains to be done.

In humans, the capacity for subjective experience is dissociable from the capacity for selfreflexive consciousness. While the latter is dependent on cortical and midbrain structures (Damasio, 1999), several authors have argued that the former is supported by the midbrain and subcortical structures (Damasio \& Carvalho, 2013; Mashour \& Alkire, 2013; Merker, 2005, 2007; B. Merker, 2013; Parvizi \& Damasio, 2001; Penfield \& Jasper, 1954). We rely especially on the work of Bjorn Merker (2007), who draws on evidence from anesthesia, vegetative state research, developmental disorders, brain damage and lesion studies to create a compelling argument that the integrated structures of the vertebrate midbrain are sufficient to support the capacity for subjective experience in humans. 
Yet while cortical damage can profoundly affect the content of conscious experience, it seems that there is no part of the cortex upon which the capacity for consciousness reliably depends (Damasio, Damasio, \& Tranel, 2012; Damasio \& Van Hoesen, 1983; Friedman-Hill, Robertson, \& Treisman, 1995; Herbet et al., 2014; Kapur et al., 1994; Merker, 2007; Penfield \& Jasper, 1954; Philippi et al., 2012). By contrast, the basic capacity for subjective experience is sensitive to damage to midbrain structures (Merker, 2007). The primary locus of action of many global anesthetics is subcortical (Alkire, Hudetz, \& Tononi, 2008; Gili et al., 2013). Emergence from anesthesia (Långsjö et al., 2012; Mashour \& Alkire, 2013), and coma or vegetative state (Schiff, 2010) are similarly predicted by the reengagement of subcortical structures.

Note here the important distinction between the capacity for subjective experience and the particular contents of experience at a given time. The human cortex obviously makes a considerable contribution to what we are aware of. Cortical damage may appear to remove whole categories of conscious content, but determining the actual effects of such damage requires careful investigation, given the complexity of inhibitory interactions with sub-cortical regions (Sprague, 1966). Similarly, there ought to be considerable variation in conscious content across phyla. Yet these are all variations which require the capacity for subjective experience in the first place.

The evidence is thus that the basic capacity for subjective experience is supported by subcortical structures. Why might this be the case? We adopt a proposal put forward by Merker (2007), who offers a functional proposal for the midbrain and subcortical basal ganglia structures that explains their role in subjective experience. These structures combine processed sensory information on the state and structure of the environment with processed information on the homeostatic needs of the organism. The outcome is a unified multimodal neural model of the agent within its environment, which is weighted by the current needs and state of the agent. Within the midbrain, different structures perform different roles in this information economy (Figure 1). This modeling gives the organism a unique, unified perspective on the world. This, argues Merker, is what makes subjective experience possible.

Two features of this proposal are particularly relevant for our argument. First, the integrated processing of spatial information in the midbrain enables a mobile animal with spatial senses to solve the so-called re-afference problem (von Holst \& Mittelstaedt, 1950). A moving animal must disambiguate environmental movement from the sensory input caused by its own motion relative to the environment. For active animals with welldeveloped spatial senses, it is computationally more effective to resolve the re-afference problem once in a unified sensory model than to resolve it in a dispersed and peripheral way for each sense independently. In addition, different senses contribute different information on how the body is moving; thus re-afference can be resolved with greater accuracy and precision by integrating information from multiple senses (Merker, 2005).

In vertebrates, the layered tectum (or superior colliculus (SC) in mammals) of the roof of the midbrain receives processed and topographically organized input from all spatially structured senses, including vision, auditory, and somatosensory inputs (Damasio \& Carvalho, 2013; Harting, Updyke, \& Van Lieshout, 1992; Klier, Wang, \& Crawford, 2001; McHaffie, Stanford, Stein, Coizet, \& Redgrave, 2005; Merker, 2007). In mammals, inputs to the SC include inputs from the vestibular system (Frens, Suzuki, Scherberger, Hepp, \& 
Henn, 1998), information on eye position (Groh \& Sparks, 1996; Knox \& Donaldson, 1995; Van Opstal, Hepp, Suzuki, \& Henn, 1995), and somatosensation (Merker, 2007). This allows the influence of self-motion on the sensory fields to be factored out of the constructed sensory model of the environment (Sparks, 1988). Hence the SC is vital for organizing motion in space, for directed attention, and for reaching and grasping for targets (Horowitz \& Newsome, 1999; Krauzlis, Liston, \& Carello, 2004; McPeek \& Keller, 2004; Zenon \& Krauzlis, 2012).
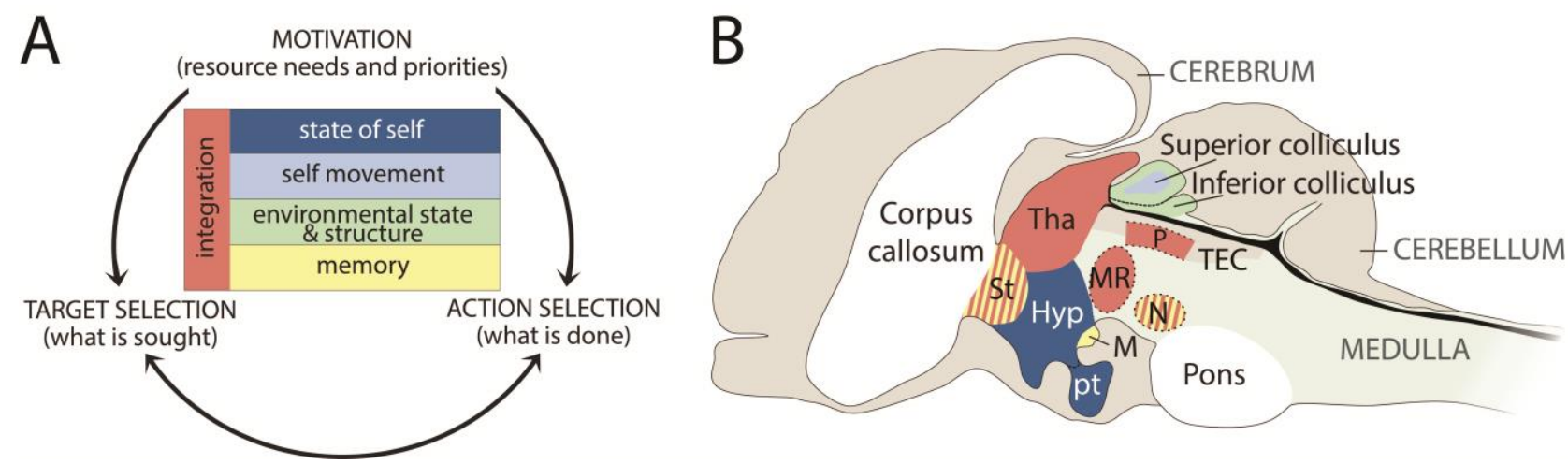

Figure 1: The vertebrate behavioral core control system. Following Merker (2007), autonomous animal decision making can be considered to involve three related domains: motivation, target selection, and action selection (A). These domains can be resolved and decisions can be made by an integrated neural system that contains information on the state of self, self-movement, environmental state, and structure and memory of prior experience. These capacities are supported by different midbrain structures (B - shown here not to scale). As a simplification, regions are colored according to their primary function(s) described in A. The superior colliculus (part of the tectum (TEC) forming the roof of the midbrain) processes multisensory spatial information (Merker 2007). Hypothalamic structures (Hyp) and associated nuclei, the pituitary (pt) and mammillary bodies (M) collate information on the physiological status of the organism referenced with prior experience, to identify needs to maintain a homeostatic optimum (Damasio \& Carvalho, 2013; Swanson, 2000). Integrative structures within the midbrain and basal ganglia, including the periaqueductal grey $(\mathrm{P})$, substantia nigra $(\mathrm{N})$, thalamus (Tha), striatum (St) and midbrain reticular formation (MR), integrate these sources of information with forms of memory to update relevance to the organism according to prior experience (McHaffie et al., 2005; Merker, 2007).

The mammalian SC thus acts as a point of convergence for spatially structured sensory information, including information about the position, orientation, and movement of the body (Masino, 1992; May, 2006; Merker, 2005; Sparks, 1988; Zenon \& Krauzlis, 2012). Processing within the SC creates a neural model of the mobile animal in space, which is essential for resolving decisions about how to react to resources around the animal.

The second relevant feature of the midbrain is that information integration within it allows for efficient action selection in complex environments. Merker (2007) has described the functions of the vertebrate midbrain as a "behavioral core control system." The midbrain supports autonomous decision making, as well as serving as the "final common pathway" for action planning. This is important, since adaptive behavior 
requires the ability to select between competing drives in rapidly changing environments (Jékely, Keijzer, \& Godfrey-Smith, 2015).

The interacting systems of the midbrain and basal ganglia support resolution of competing behavioral options by compiling information on the location and availability of resources, the meaning and relevance of stimuli to the organism, and its physiological needs (Figure 1). The hypothalamic structures and associated nuclei that form the floor of the midbrain collate information on the physiological status of the organism (Swanson, 2000). These nuclei motivate and participate in the initiation of behavior directed at maintaining the animal in optimal physiological condition (Damasio \& Carvalho, 2013; Swanson, 2000). The integrative structures of the basal ganglia and midbrain utilize the information on the status and needs of the animal together with information on where the animal is situated relative to available resources in order to prioritize resource seeking, resolve competing needs, and select targets and actions (McHaffie et al., 2005; Merker, 2007; Gurney, Prescott, \& Redgrave, 2001; Redgrave, Prescott, \& Gurney, 1999).

Possible actions are set in competition, and the winner of the competition gains effective control of action (Gurney et al., 2001; Merker, 2007; Redgrave et al., 1999). This in turn feeds back into topographically oriented spatial information generated by the SC, generating "task-relevance maps" (Navalpakkam, Arbib, \& Itti, 2005) which further guide active exploration of the environment. The motivational and physiological states of the organism prioritize target and action selection, but the location and availability of targets is also a key factor influencing what is targeted and what next action will be taken (Merker, 2007).

The midbrain thus allows for unified sensory processing and decision making without invoking a separate control system utilizing the information to make a decision (McHaffie et al., 2005; Redgrave et al., 1999) or regressing to a "Cartesian Theatre" (Dennett, 1991). Merker's (2007) conceptual behavioral core control system emphasizes how domains critical to decision making, target selection, action selection and motivation must interact since the interactions are critical to effective decision making. Crucially, the midbrain integrates particular types of information into a unified model. Thus it is not integration per se that matters (as suggested, for example, by Tononi $(2004,2008$; Tononi \& Koch, 2015), but the dynamic and ongoing connection between perception, interoception, associative memory, and motor feedback.

\section{Parallels Between Vertebrate and Insect Brains}

The functional parallels between the vertebrate midbrain and insect brains form the centerpiece of our argument. While there is no obvious similarity in the gross anatomy (Figure 2), there is an overall similarity in functional architecture between the vertebrate midbrain and the insect brain as a whole. (A full presentation may be found in Barron \& Klein, 2016).

In the insect brain, the central complex (CX) is specialized for the processing of spatial information and the organization of movement (Heinze \& Homberg, 2007; Pfeiffer \& Homberg, 2014; Plath \& Barron, 2015). The CX is functionally analogous to the SC in many respects. The $\mathrm{CX}$ processes multiple sources of spatial information drawn from different senses to locate the moving animal in space. This includes spatially structured 
information on plane-polarized light (Bockhorst \& Homberg, 2015; Heinze \& Homberg, 2007; Lin et al., 2013; Pfeiffer \& Homberg, 2014); spatially structured visual information on moving objects (Kathman, Kesavan, \& Ritzmann, 2014; Rosner \& Homberg, 2013; Seelig \& Jayaraman, 2013; Weir, Schnell, \& Dickinson, 2014) corrected for self-motion to resolve the re-afference problem (Seelig \& Jayaraman, 2013); and spatially structured mechanosensory and proprioceptive information in cockroaches (Guo \& Ritzmann, 2013), Drosophila (Seelig \& Jayaraman, 2015), and crickets (Kai \& Okada, 2013). Like the mammalian SC, the insect CX is necessary for targeting, reaching, orientation, and directed movement (Kai \& Okada, 2013; Kathman et al., 2014; Pfeiffer \& Homberg, 2014). Processing within the CX enables the insect to maintain a course using either visual or proprioceptive information (Seelig \& Jayaraman, 2015).

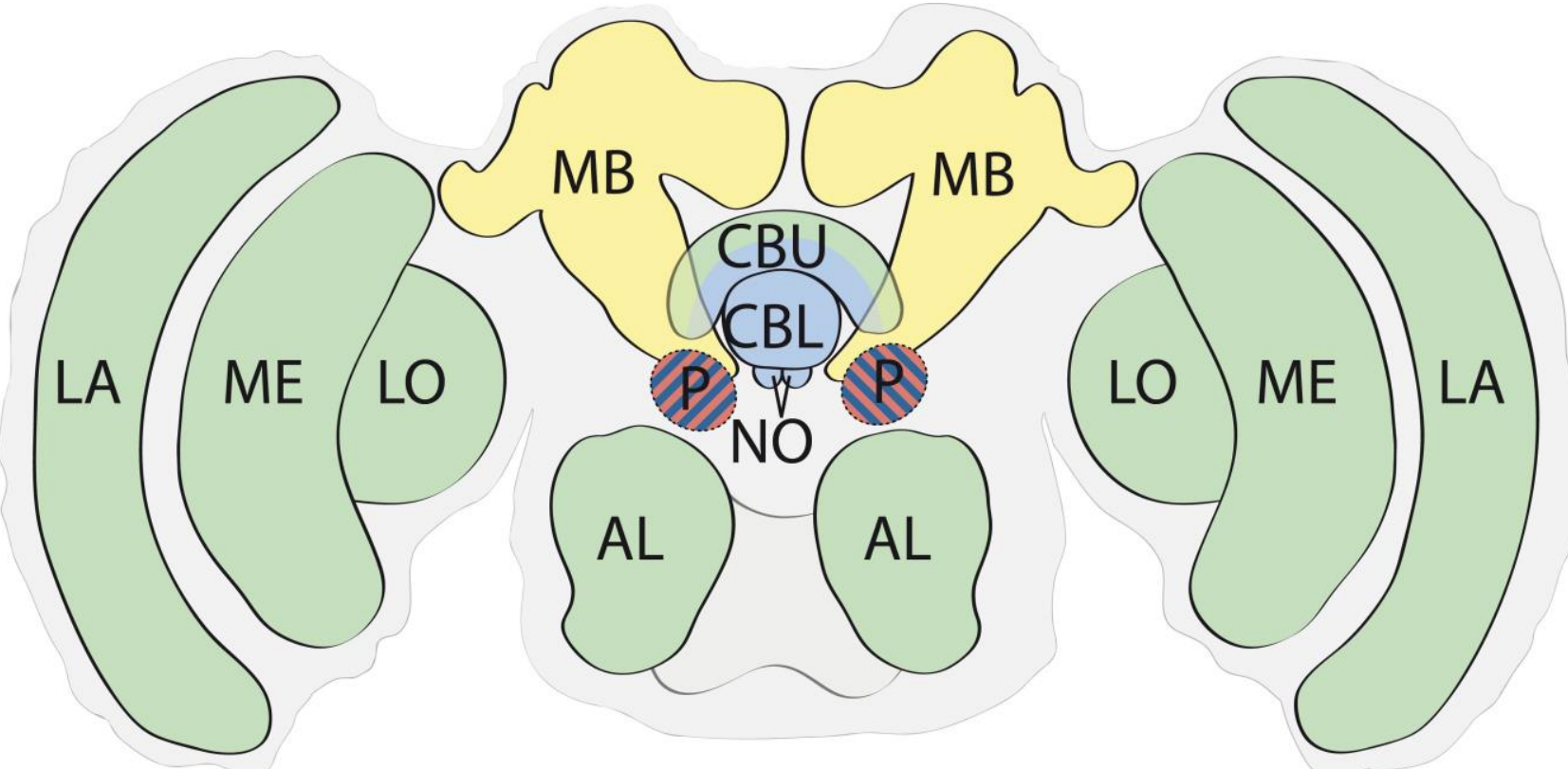

Figure 2: Basic functional anatomy of the insect brain (not to scale). The structures of the insect brain are functionally analogous to those functions of the vertebrate midbrain described in Figure 1. (Regions are colored to highlight the functional analogy with Figure 1A.) Sensory lobes, of the antennae (AL) and visual system (lamina (LA), medulla (ME) and lobula (LO)) contribute information on environment state and structure (Galizia, 2014; Horridge, 2005). The mushroom bodies (MB) support learning and memory (Bazhenov et al., 2013; Heisenberg, 2003; Huerta, Nowotny, Garcia-Sanchez, Abarbanel, \& Rabinovich, 2004; Menzel, 2001; Schwaerzel et al., 2003). The central complex (CX) is anatomically variable between insect orders, but is typically composed of the central body upper (CBU), central body lower (CBL), and noduli (NO). It is specialised for processing spatial information (Kathman et al., 2014; Pfeiffer \& Homberg, 2014; Pfeiffer \& Crailsheim, 1998; Plath \& Barron, 2015; Seelig \& Jayaraman, 2015). The protocerebrum (P) is large and anatomically complicated region, and connects these other regions. It is premotor and serves as a final common path for all sensory information either directly from the lobes, or via the MB and CX pathways. Modulatory and inhibitory connections to and within the protocerebrum convey information on physiological state (Galizia, 2014; Parnas et al., 2013). The region is involved in both integration of information and processing of state of self, hence the hatched shading. 
The CX sends outputs to and receives inputs from protocerebral structures, particularly the bulb and lateral accessory lobe (Pfeiffer \& Homberg, 2014) (Figure 2). The protocerebrum is composed of a number of interconnected subregions that are both premotor and a point of convergence for outputs from the sensory lobes, the CX, and the mushroom bodies (MB) (Ito et al., 2014; Strausfeld, 1976, 2012; Strausfeld \& Hirth, 2013).

In the vertebrate midbrain and basal ganglia, there are several integrative loci that support learning and memory so that the organism can update its responses to stimuli according to its experience (Figure 1A). In insects, this capacity is supported by the MB (Bazhenov, Huerta, \& Smith, 2013; Fahrbach, 2006; Galizia, 2014). Connectivity between the intrinsic neurons that make up the MB (Kenyon cells) and their inputs and outputs is plastic, supporting experience-dependent changes in how stimuli are represented by the population of neurons in the $\mathrm{MB}$, and the downstream neurons that are activated or inhibited (Barron, Gurney, Meah, Vasilaki, \& Marshall, 2015; Galizia, 2014).

Within the protocerebrum, and connecting to the $\mathrm{CX}$ and $\mathrm{MB}$, there are highly specialized modulatory neuron clusters that modify neural activity according to the physiological and motivational state of the insect (Andretic, van Swinderen, \& Greenspan, 2005; Burke et al., 2012; Krashes et al., 2009; Søvik, Perry, \& Barron, 2015). These specialized circuits modify how the insect responds to events according to its subjective internal state such as arousal, sleep, satiation, hunger, and reward (Andretic et al., 2005; Burke et al., 2012; Krashes et al., 2009; Liu, Liu, Kodama, Driscoll, \& Wu, 2012; Søvik et al., 2015). This is functionally parallel to the hypothalamic nuclei in vertebrates.

Competitive processing within the protocerebrum contributes to effective decision making and action selection utilizing all available sensory information as well as information on the state of the insect (Barron et al., 2015; Galizia, 2014; Liang et al., 2013; Parnas, Lin, Huetteroth, \& Miesenböck, 2013). Hence competitive processing within the protocerebrum is functionally similar to the vertebrate basal ganglia system.

The insect classifies and weights environmental stimuli according to their relevance to the insect (Strube-Bloss, Nawrot, \& Menzel, 2011). In addition, insects selectively filter the processing of sensory information to prioritize the stimuli of the greatest immediate relevance and discount stimuli of no subjective relevance. This has been demonstrated for both honey bees (Apis mellifera) and Drosophila (Paulk et al., 2014; Sareen, Wolf, \& Heisenberg, 2011; van Swinderen, 2005; van Swinderen \& Greenspan, 2003) in which the neural representation of the environment is both subjective and egocentric.

In summary, there are significant parallels between the functional organization of the insect brain and that of the vertebrate midbrain behavioral core control system. Both systems have specialized regions for processing the position of the moving animal in space. In both systems action selection is resolved by combining information on position with information on the environment, the relevance of stimuli in the environment to the animal, and the state of the animal (Figures 1, 2). In vertebrates the channels of information are sufficiently unified such that the system as a whole creates a functional representation of the state of the mobile animal in space as a solution for effective decision making. 
As we have argued, processing of this kind supports the capacity for a subjective experience of the environment. Processing in the insect brain is unified to a similar degree, for similar reasons. Hence we propose that the insect brain can also support a capacity for subjective experience.

\section{The Evolutionary Origins of Subjective Experience}

We have argued that subjective experience arose as a consequence of the integrated behavioral control systems for effective decision making and action selection. In both vertebrate and insect lineages, the control systems we have described are highly conserved and basal to the groups (Feinberg \& Mallatt, 2016; Strausfeld, 2012). The early evolution and high degree of conservation of these neural systems is understandable given that they resolve fundamental problems for mobile animals. But if these unified behavioral control systems are ancient, then it is possible that subjective experience itself is similarly ancient.

The key structural elements of the vertebrate behavioral core control system are all present and functional in lampreys (extant, primitive jawless fish) (Feinberg \& Mallatt, 2013; Grillner, Robertson, \& Stephenson-Jones, 2013; Merker, 2005; Stephenson-Jones, Samuelsson, Ericsson, Robertson, \& Grillner, 2011; I. C. Zompa \& Dubuc, 1996; Iolanda C. Zompa \& Dubuc, 1998). These structures are present in the basal vertebrates and conserved across all extant groups. It has also been proposed that similar structures might have been present in the fossil vertebrate Haikouichthys from the Cambrian (Feinberg \& Mallatt, 2013; Feinberg \& Mallatt, 2016). Haikouichthys is reconstructed as a fish-like active swimmer with large image-forming eyes (Shu et al., 2003). If so, then subjective experience in vertebrates is at least as old as the Cambrian (Feinberg \& Mallatt, 2013; Feinberg \& Mallatt, 2016).

The insect behavioral core control system has similarly ancient origins. The CX is basal to insects. It almost certainly predates the divergence of insects, crustaceans and arachnids since homologous structures are found in all three groups (Homberg, 2008; Loesel, Nässel, \& Strausfeld, 2002; Pfeiffer \& Homberg, 2014). Some Cambrian arthropods had well-developed cephalic ganglia with structural similarities to extant crustacean and insect brains (Ma, Hou, Edgecombe, \& Strausfeld, 2012). It is reasonable to suppose that a version of the extant insect behavioral core control system was present in at least some Cambrian arthropods to support their presumed active foraging and hunting lifestyles (Trestman, 2013).

It is presently unclear whether the insect and vertebrate behavioral core control systems evolved independently. Strausfeld and Hirth (2013) have argued for a deep homology between the insect CX and associated structures and vertebrate basal ganglia. If this interpretation is correct, it would imply that a form of behavioral core control system may even predate the divergence of these groups. 


\section{Defending the Insect Brain}

Our argument depends on functional claims about the insect brain. Much of this is recent science. Insect brains have been consistently underestimated, and it is worth addressing some of those misunderstandings.

Some have denied that insects have the requisite functional organization for subjective experience. This includes Merker himself, (2007), who cites Altman's (1989) characterization of the insect brain as a decentralized system with the cephalic ganglion a locus for sensory input but with action selection resolved locally at the motor systems of the segmental ganglia. Altman's (1989) view of the insect nervous system was itself inspired by Brooks's (1989) subsumption architectures for behavioral control of a walking robot.

This view of the insect brain is outdated. The cephalic ganglion clearly executes a command function over the behavioral system since reasonably small and neurochemically specific lesions of the protocerebrum proximal to the CX can completely incapacitate an insect by removing volitional behavioral control (Libersat \& Gal, 2014).

Others have focused not on organization but on neuron number. The gulf between the size of insect and mammalian brains is indeed enormous. The honey bee has less than a million neurons in the cephalic ganglion - and this is a very large brain for an insect. By comparison, a mouse (Mus musculus) has 68 million neurons in the brain, a rhesus monkey (Macaca mullata) 6.4 billion and a human 86 billion (Herculano-Houzel, 2016).

Many writers on insects have thus focused on the limitations imposed by their comparatively tiny brains. Feinberg and Mallatt (2013) have argued that most of the vertebrates have a capacity for subjective experience. Yet they are equivocal on whether insects have the capacity, precisely because of neuron number (Feinberg \& Mallatt, 2016).

We believe it is inappropriate to focus on neuron number alone. Functional organization is what matters. Neuron number is important only insofar as it might affect functional organization. Insect brains are small, but they have enough neurons to do the job, and that is all that matters.

Insect brains are also extremely economical in their use of neurons. While higher vertebrates have large neural loci for processing internal states and motivations, insects perform analogous functions with clusters of just a few neurons (Andretic et al., 2005; Burke et al., 2012; Krashes et al., 2009; Søvik et al., 2015). The human nucleus accumbens (part of the reward system of the vertebrate brain) is larger than the whole honey bee brain, but honey bees organize analogous reinforcing functions of the nucleus accumbens with clusters of just a few broad-field neuromodulatory neurons (Perry \& Barron, 2013; Søvik et al., 2015).

The larger vertebrate brains are very likely more robust, degenerate, and precise, and have greater capacities for storage and parallel processing than the small and economical insect brains (Chittka \& Niven, 2009). But we agree with Chittka and Niven (2009) that 
the qualitative differences in processing capacity of brains at the insect and vertebrate scales are not as great as they might seem given the differences in neuron number.

\section{Why There Is a Lower Bound}

Finally, some have postulated subjective experience in insects because they think that consciousness is even more widespread. For example, authors have postulated subjective experience in plants (Pelizzon \& Gagliano, 2015), in any reasonably complex system (see Tononi, 2004), or even that it is a fundamental feature of the universe akin to spin and electric charge (Strawson, 2006). Such views would obviously imply that insects are conscious (though that is far from their most striking prediction).

We disagree. We think there is a cutoff. Many animals, all plants, and (as far as we know) all currently existing man-made artifacts fall below the line. Without the right kind of centralized integration and modeling, an organism cannot be conscious.

Box jellyfish, for example, are highly mobile and use well-developed lensed eyes and chemosensors to actively hunt prey (Garm, Oskarsson, \& Nilsson, 2011; Kingsford \& Mooney, 2014). Yet they (like all Cnidarians) have a decentralized nervous system, and a completely decentralized behavioral control system. Sense organs independently modulate activity in local regions of the sensory net and muscle walls to steer the animal (Petie, Garm, \& Nilsson, 2011).

While centralized processing of all available exteroceptive and interoceptive sensory information is necessary for subjective experience, centralization alone is not sufficient. What is processed, and how it is processed, also matters. This requirement may itself seem churlish. Having gone so far, why deny conscious experience to (say) worms?

We think the answer is instructive. Consider the nematode Caenorhabditis elegans. The nervous system of the nematode is centralized, and famously well characterized. It includes thermo-, mechano-, chemo-, and nociceptors, and interoceptive senses related to physiological state (Gordus, Pokala, Levy, Flavell, \& Bargmann, 2015) and the passing of time (de Bono \& Maricq, 2005). These are integrated at the level of an array of interneurons that activate motor neurons (de Bono \& Maricq, 2005; Kato et al., 2015). Nematodes are thus able to integrate multiple forms of sensory input using a centralized nervous system. Action selection in nematodes is driven by shifts in global brain dynamics (Kato et al., 2015).

Nematodes can learn, and hence can change how they react to stimuli (Gordus et al., 2015). They also have basic memory and can retain learned behavioral changes (Ardiel \& Rankin, 2010). But nematodes have no spatial senses. They have no capacity to locate themselves in their environment or to detect the relative position of objects around them. This has significant consequences. Because there are no spatial dimensions to a nematode's sensory world, the only way nematodes can interrelate sensory information is by contiguity. This is supported by their neural network and basic forms of learning and memory (Ardiel \& Rankin, 2010; Gordus et al., 2015).

Nematodes cannot perform the integrated spatiotemporal modeling that characterizes the vertebrate midbrain and the insect brain. All nematode behavior is a direct reaction 
to their immediate state. There is no evidence of planning in nematodes, nor structured search behavior. Hungry nematodes respond to starvation with increased locomotion and dispersal in a random rather than directed search (Artyukhin, Yim, Cheong, \& Avery, 2015; Lüersen, Faust, Gottschling, \& Döring, 2014).

That immediate reactivity is in sharp contrast to the behavior of hungry rodents, ants, and bees, who will navigate to places where they have previously encountered food when hungry (Oades \& Isaacson, 1978; Seeley, 1995; Wehner, 2013). Hence, in mammals and insects, homeostatic drives direct behavior to where resources are expected to be, even if they are not currently there. Such anticipatory behavior is not possible for nematodes, who have no capacity to form any spatial relations between arbitrary objects.

The final point is important. The key feature of the integrated core control system is that it allows the interaction of diverse and novel elements in a single process. That is what makes sensation and action integrated. That is why the basic capacity for subjective experience can be extended to include ever more complicated contents as brains expand. It allows organisms to extract synthetic interrelations between elements. And of course that is what allows the organism to represent itself and its place within a broader representation of the world.

We have emphasized the importance of mechanisms that support integrated modeling of the environment. The sense of "modeling" we have in mind is a relatively lightweight one. It is important to note that it does not require the construction of offline, non-dynamic representations. Models can be constructed dynamically rather than stored statically. The important thing for our purposes is the process of integration rather than static representation. Our view is thus compatible with (for example) Barbara Webb's (2004, 2006) critiques of representationalist thinking in insect neuroscience.

That said, we believe that this integrative process is representational in a straightforward sense. We have little interest in arguing about the terms "representation" and "model." The important fact for present purposes is that organisms like nematodes lack any such ability. As a consequence, a nematode cannot locate itself in space, nor position itself relative to things around it, nor relate itself to its own distant past, nor relate its current needs in arbitrary ways to any of this in order to give them meaning and context. The nematode nervous system just transforms the immediate sensory environment into immediate motor responses. Of course, for the simple environments that nematodes are bound to, and for the simple responses they can enact, this form of behavioral control system is more than sufficient. But we do not believe that with almost no capacity to interrelate sensory information the nematode nervous system supports a capacity for subjective experience.

\section{Conclusion: Making Progress on Hard Problems}

We have emphasized throughout the importance of a mobile lifestyle in driving the evolution of consciousness. The importance of mobility for driving neural evolution is not a new idea, but it is worth emphasizing. Mobility presented a fundamentally new sort of challenge to organisms, one that modern AI still finds extremely difficult (Brooks, 1999). As Moravec puts it (1984), 
I conclude that a mobile way of life favors general solutions that tend towards intelligence, while non-motion favors deep specializations. A fixed organism is repeatedly exposed to a limited set of problems and opportunities, and will do better in the long run if it becomes good at dealing with this limited range. A roving creature encounters fewer instances of a greater variety of different conditions, and does better with general methods, even if such generality is more expensive, or results in poorer performance in specific instances.

The cumulative effect of this difference in selection pressure is enormous, as evidenced by clams and octopus, or plants and animals. Trees are as successful and dominant in their niche as humans are in theirs, but the life of a tree does not demand high speed general purpose perception, flexible planning and precisely controlled action.

Centralization in the service of action selection is, we have argued, the advance that allowed for the evolution of subjective experience.

Of course, we might be wrong. Many reject Merker's theory, or even the basic premise that the midbrain is key to subjective experience. Alternatives to Merker might fail to generalize to invertebrates. We have emphasized the importance of a unified perspective on the world as a key feature of subjective experience (Christoff et al., 2011). We might have left out other neural features that are necessary for subjective experience, such as an explicit representation of a temporal dimension (Kant, 1999). Insects may lack these (though see Skorupski \& Chittka, 2006).

That said, we emphasize that disagreement of this sort should ultimately rest on empirical facts: that is, on structural, functional, and comparative hypotheses about brains. In that sense, our position is a thoroughly naturalistic one. We have not attempted to say anything about the hard problem of consciousness (Chalmers, 1996). Instead, we follow the advice of Penfield \& Rasmussen (1950) to the effect that:

...neurologists should push their investigations into the neurologic mechanism associated with consciousness and should inquire closely into the localization of that mechanism without apology and without undertaking responsibility for the theory of consciousness (Penfield \& Rasmussen, 1950).

We think that a contemporary study of consciousness resembles the study of vital forces before modern physiology (Cruse \& Schilling, 2015). What seemed like a great gap between the organic and the inorganic was ultimately bridged by the development of appropriate scientific concepts.

We have a similar take on the hard problem: It is difficult because we don't yet have the concepts for assessing what a satisfying answer could even look like. The solution, however, is to press on as best we can with empirical inquiry, revising our concepts as we go. We have offered an ostensive definition of the phenomenon we care about and we have given a mechanistic story about how that phenomenon is realized. The search for mechanisms does not require anything like a clear concept at the outset (Craver, 2007). 
Rather, a search for mechanisms can be the means of clarifying our concepts (Wimsatt, 2007) and thereby moving past seemingly intractable difficulties. We hope that this will also turn out to be the case for the study of consciousness. Insects, and invertebrates more generally, have often been overlooked as potential players in this story. We hope to correct that oversight.

\section{Acknowledgments}

In addition to those thanked in Barron \& Klein (2016), thanks to Bruno van Swinderen and attendees at the 2016 SydPP meeting for additional feedback. Figures 1 and 2 were created by Marcus J.A. Plath. This work was supported by Australian Research Council Future Fellowship project no. FT140100452 awarded to A.B.B. and Australian Research Council Future Fellowship project no. FT140100422 awarded to C.K.

Call for Commentary: Animal Sentience publishes Open Peer Commentary on all accepted target articles. Target articles are peer-reviewed. Commentaries are editorially reviewed. There are submitted commentaries as well as invited commentaries. Commentaries appear as soon as they have been revised and accepted. Target article authors may respond to their commentaries individually or in a joint response to multiple commentaries.

Instructions: http://animalstudiesrepository.org/animsent/guidelines.html

\section{References}

Alkire, M. T., Hudetz, A. G., \& Tononi, G. (2008). Consciousness and anesthesia. Science, 322(5903), 876-880.

Altman, J. S., \& Kien, J. (1989). New models for motor control. Neural Computation, 1, 173183.

Andretic, R., van Swinderen, B., \& Greenspan, R. J. (2005). Dopaminergic modulation of arousal in Drosophila. Current Biology, 15, 1165-1175.

Ardiel, E. L., \& Rankin, C. H. (2010). An elegant mind: Learning and memory in Caenorhabditis elegans. Learning and Memory, 17, 191-201.

Artyukhin, A. B., Yim, J. J., Cheong, M. C., \& Avery, L. (2015). Starvation-induced collective behavior in C. elegans. Scientific Reports, 5, 10647. doi: 10.1038/srep10647

Barron, A. B., \& Klein, C. (2016). What insects can tell us about the origins of consciousness. Proceedings of the National Academy of Science of the United States of America, 113(18), 4900-4908.

Barron, A. B., Gurney, K. N., Meah, L. F. S., Vasilaki, E., \& Marshall, J. A. R. (2015). Decisionmaking and action selection in insects: inspiration from vertebrate-based theories. Frontiers in Behavioral Neuroscience, 9, 216. doi: 10.3389/fnbeh.2015.00216

Bayne, T., Hohwy, J., \& Owen, A. M. (2016). Are there levels of consciousness? Trends in Cognitive Sciences, 20(6), 405-413.

Bazhenov, M., Huerta, R., \& Smith, B. (2013). A computational framework for understanding decision making through integration of basic learning rules. Journal of Neuroscience, 33(13), 5686-5697.

Block, N. (1995). On a confusion about a function of consciousness. Behavioral and Brain Sciences, 18(02), 227-287.

Bockhorst, T., \& Homberg, U. (2015). Amplitude and dynamics of polarization-plane signaling in the central complex of the locust brain. Journal of Neurophysiology, 113, 3291-3311. 
Brooks, R. A. (1989). A robot that walks; Emergent behaviors from a carefully evolved network. Neural Computation, 1, 253-262.

Brooks, R. A. (1999). Cambrian intelligence: The early history of the new AI. Cambridge, MA: MIT Press.

Burke, C. J., Huetteroth, W., Owald, D., Perisse, E., Krashes, M. J., Das, G., Gohl, D., Silies, M., Certel, S., \& Waddell, S. (2012). Layered reward signalling through octopamine and dopamine in Drosophila. Nature, 492(7429), 433-437. doi: 10.1038/nature11614

Chalmers, D. (1996). The conscious mind: In search of a fundamental theory. New York: Oxford University Press.

Chittka, L., \& Niven, J. (2009). Are bigger brains better? Current Biology, 19, R995-R1008. Christoff, K., Cosmelli, D., Legrand, D., \& Thompson, E. (2011). Specifying the self for cognitive neuroscience. Trends in Cognitive Sciences, 15(3), 104-112.

Craver, C. F. (2007). Explaining the brain. New York: Oxford University Press.

Cruse, H., \& Schilling, M. (2015). Mental states as emergent properties: from walking to consciousness. Open MIND, 9, 1-38.

Damasio, A. (1999). The feeling of what happens: Body and emotion in the making of consciousness. Orlando: Harcourt Inc.

Damasio, A., \& Carvalho, G. B. (2013). The nature of feelings: evolutionary and neurobiological origins. Nature Reviews Neuroscience, 14, 143-152.

Damasio, A., \& Van Hoesen, G. (1983). Emotional disturbances associated with focal lesions of the limbic frontal lobe. In P. Satz \& K. M. Heilman (Eds.), Neuropsychology of Human Emotion (pp. 85-110). New York: Guilford Press

Damasio, A., Damasio, H., \& Tranel, D. (2012). Persistence of feelings and sentience after bilateral damage of the insula. Cerebral Cortex, 23(4), 833-846.

De Bono, M., \& Maricq, A. V. (2005). Neuronal substrates of complex behaviors in C. elegans. Annual Review of Neuroscience, 28, 451-501.

Dennett, D. C. (1991). Consciousness explained. Boston: Little, Brown, \& co.

Edelman, G. M. (2003). Naturalizing consciousness: a theoretical framework. Proceedings of the National Academy of Sciences, 100(9), 5520-5524.

Fahrbach, S. E. (2006). Structure of the mushroom bodies of the insect brain. Annual Review of Entomology, 51, 209-232.

Feinberg, T. E., \& Mallatt, J. (2013). The evolutionary and genetic origins of consciousness in the Cambrian Period over 500 million years ago. Frontiers in Psychology, 4(667), 1-27.

Feinberg, T. E., \& Mallatt, J. M. (2016). The ancient origins of consciousness: How the brain created experience. Cambrige, MA: MIT Press.

Frens, M. A., Suzuki, Y., Scherberger, H., Hepp, K., \& Henn, V. (1998). The collicular code of saccade direction depends on the roll orientation of the head relative to gravity. Experimental Brain Research, 120, 283-290.

Friedman-Hill, S., Robertson, L. C., \& Treisman, A. (1995). Parietal contributions to visual feature binding: evidence from a patient with bilateral lesions. Science, 269(5225), 853855.

Galizia, C. G. (2014). Olfactory coding in the insect brain: data and conjectures. European Journal of Neuroscience, 39, 1784-1795.

Garm, A., Oskarsson, M., \& Nilsson, D.-E. (2011). Box jellyfish use terrestrial visual cues for navigation. Current Biology, 21, 798-803.

Gili, T., Saxena, N., Diukova, A., Murphy, K., Hall, J. E., \& Wise, R. G. (2013). The thalamus and brainstem act as key hubs in alterations of human brain network connectivity induced by mild propofol sedation. The Journal of Neuroscience, 33(9), 4024-4031. Gordus, A., Pokala, N., Levy, S., Flavell, S. W., \& Bargmann, C. L. (2015). Feedback from network states generates variability in a probabilistic olfactory circuit. Cell, 161, 215-227. 
Grillner, S., Robertson, B., \& Stephenson-Jones, M. (2013). The evolutionary origin of the vertebrate basal ganglia and its role in action selection. Journal of Physiology, 591(22), 5425-5431.

Groh, J. M., \& Sparks, D. L. (1996). Saccades to somatosensory targets. III. Eye-dependent somatosensory activity in primate superior colliculus. Journal of Neurophysiology, 75, 439-453.

Guo, P., \& Ritzmann, R. (2013). Neural activity in the central complex of the cockroach brain is linked to turning behaviors. Journal of Experimental Biology, 216, 992-1002. Gurney, K. N., Prescott, T. J., \& Redgrave, P. (2001). A computational model of action selection in the basal ganglia I: A new functional anatomy. Biological Cybernetics, 84, 401-410.

Harting, J. K., Updyke, B. V., \& Van Lieshout, D. P. (1992). Corticotectal projections in the cat: Anterograde transport studies of twenty-five cortical areas. Journal of Comparative Neurology, 328, 379-414.

Heinze, S., \& Homberg, U. (2007). Maplike representation of celestial E-vector orientations in the brain of an insect. Science, 315, 995-997.

Heisenberg, M. (2003). Mushroom body memoir: from maps to models. Nature Reviews Neuroscience, 4, 266-275.

Herbet, G., Lafargue, G., de Champfleur, N. M., Moritz-Gasser, S., le Bars, E., Bonnetblanc, F. C., \& Duffau, H. (2014). Disrupting posterior cingulate connectivity disconnects consciousness from the external environment. Neuropsychologia, 56, 239-244. Herculano-Houzel, S. (2016). The human advantage: a new understanding of how our brain became remarkable. Cambridge, MA: MIT Press.

Homberg, U. (2008). Evolution of the central complex in the arthropod brain with respect to the visual system. Arthropod Structure and Development, 37, 347-362. Horowitz, G. D., \& Newsome, W. T. (1999). Separate signals for target selection and movement specification in the superior colliculus. Science, 284, 1158-1161.

Horridge, A. (2005). What the honeybee sees: a review of the recognition system of Apis mellifera. Physiological Entomology, 30, 2-13.

Huerta, R., Nowotny, T., Garcia-Sanchez, M., Abarbanel, H. D. L., \& Rabinovich, M. I. (2004). learning classification in the olfactory system of insects. Neural Computation, 16, 16011640.

Ito, K., Shinomiya, K., Ito, M., Armstrong, J. D., Boyan, G., Hartenstein, V., Harzsch, S., Heisenberg, M., Homberg, U., Jenett, A., Keshishian, H., Restifo, L. L., Rössler, W., Simpson, J. H., Strausfeld, N. J., Strauss, R., \& Vosshall, L. B. (2014). A systematic nomenclature for the insect brain. Neuron, 81(4), 755-765. doi: 10.1016/j.neuron.2013.12.017

Jékely, G., Keijzer, F., \& Godfrey-Smith, P. (2015). An option space for early neural evolution. Philosophical Transactions of the Royal Society B, 370(1684). doi: 10.1098/rstb.2015.0181

Kai, K., \& Okada, R. (2013). Characterization of locomotor-related spike activity in protocerebrum of freely walking cricket. Zoological Science, 30, 591-601.

Kant, I. (1999). Critique of pure reason: The cambridge edition of the works of Immanuel Kant (P. Guyer \& A. W. Wood, Eds.). Cambridge: Cambridge University Press.

Kapur, N., Ellison, D., Parkin, A. J., Hunkin, N. M., Burrows, E., Sampson, S., \& Morrison, E. (1994). Bilateral temporal lobe pathology with sparing of medial temporal lobe structures: Lesion profile and pattern of memory disorder. Neuropsychologia, 32(1), 2338.

Kathman, N., Kesavan, M., \& Ritzmann, R. (2014). Encoding wide-field motion and direction in the central complex of the cockroach Blaberus discoidalis. Journal of Experimental Biology, 217, 4079-4090. 
Kato, S., Kaplan, H. S., Schrödel, T., Skora, S., Lindsay, T. H., Yemini, E., Lockery, S., \& Zimmer, M. (2015). Global brain dynamics embed the motor command sequence of Caenorhabditis elegans. Cell, 163, 1-14.

Kingsford, M. J., \& Mooney, C. J. (2014). The ecology of box jellyfishes (Cubozoa). In K. A. Pitt \& C. H. Lucas (Eds.), Jellyfish blooms (pp. 267-303). New York: Springer

Klier, E. M., Wang, H., \& Crawford, J. D. (2001). The superior colliculus encodes gaze commands in retinal coordinates. Nature Neuroscience, 4, 627-632.

Knox, P. C., \& Donaldson, I. M. L. (1995). The effect of afferent signals from extraocular muscles on visual responses of cells in the optic tectum of the pigeon. Proceedings of the Royal Society of London, Series B, Biological Sciences, 259, 285-291.

Krashes, M. J., DasGupta, S., Vreede, A., White, B., Armstrong, J. D., \& Waddell, S. (2009). A neural circuit mechanism integrating motivational state with memory expression in Drosophila. Cell, 139, 416-427.

Krauzlis, R. J., Liston, D., \& Carello, C. D. (2004). Target selection and the superior colliculus: goals, choices and hypotheses. Vision Research, 44, 1445-1451.

Långsjö, J. W., Alkire, M. T., Kaskinoro, K., Hayama, H., Maksimow, A., Kaisti, K. K., Aalto, S., Aantaa, R., Jääskeläinen, S. K., Revonsuo, A., \& Scheinin, H. (2012). Returning from oblivion: imaging the neural core of consciousness. The Journal of Neuroscience, 32(14), 4935-4943.

Liang, L., Li, Y., Potter, C. J., Yizhar, O., Deisseroth, K., Tsien, R. W., \& Luo, L. (2013). GABAergic projection neurons route selective olfactory inputs to specific higher-order neurons. Neuron, 79, 917-931.

Libersat, F., \& Gal, R. (2014). Wasp voodoo rituals, venom-cocktails, and the zombification of cockroach hosts. Integrative and Comparative Biology, 54(2), 129-142.

Lin, C., Chuang, C. C., Hua, T., Chen, C. C., Dickson, B. J., Greenspan, R. J., \& Chiang, A. S. (2013). A comprehensive wiring diagram of the protocerebral bridge for visual information processing in the Drosophila brain. Cell Reports, 3, 1739-1753.

Liu, Q., Liu, S., Kodama, L., Driscoll, M. R., \& Wu, M. N. (2012). Two dopaminergic neurons signal to the dorsal fan-shaped body to promote wakefulness in Drosophila. Current Biology, 22(22), R949-R951.

Loesel, R., Nässel, D., \& Strausfeld, N. (2002). Common design in a unique midline neuropil in the brains of arthropods. Arthropod Structure \& Development, 31(1), 77-91.

Lüersen, K., Faust, U., Gottschling, D.-C., \& Döring, F. (2014). Gait-specific adaptation of locomotor activity in response to dietary restriction in Caenorhabditis elegans. Journal of Experimental Biology, 217, 2480-2488.

Ma, X., Hou, X., Edgecombe, G. D., \& Strausfeld, N. J. (2012). Complex brain and optic lobes in an early Cambrian arthropod. Nature, 490, 258-261. doi: 10.1038/nature11495

Mashour, G. A., \& Alkire, M. T. (2013). Evolution of consciousness: phylogeny, ontogeny, and emergence from general anesthesia. Proceedings of the National Academy of Sciences, 110(Supplement 2), 10357-10364.

Masino, T. (1992). Brain-stem control of orienting movements - intrinsic coordinate systems and underlying circuitry. Brain Behaviour and Evolution, 40, 98-111.

May, P. J. (2006). The mammalian superior colliculus: laminar structure and connections. Progress in Brain Research, 151, 321-378.

McHaffie, J. G., Stanford, T. R., Stein, B. E., Coizet, V., \& Redgrave, P. (2005). Subcortical loops through the basal ganglia. Trends in Neurosciences, 28, 401-407.

McPeek, R. M., \& Keller, E. L. (2004). Deficits in saccade target selection after inactivation of the superior colliculus. Nature Neuroscience, 7, 757-763.

Menzel, R. (2001). Cognitive architecture of a mini-brain: the honeybee. Trends in Cognitive Sciences, 5(2), 62-71. doi: 10.1016/s1364-6613(00)01601-6 
Merker, B. (2005). The liabilities of mobility: A selection pressure for the transition to consciousness in animal evolution. Consciousness and Cognition, 14, 89-114.

Merker, B. (2007). Consciousness without a cerebral cortex: A challenge for neuroscience and medicine. Behavioral and Brain Sciences, 30, 63-81. doi: 10.1017/S0140525X07000891

Merker, B. (2013). The efference cascade, consciousness, and its self: naturalizing the first person pivot of action control. Frontiers in Psychology, 4, 501.

Moravec, H. P. (1984). Locomotion, vision and intelligence. In M. Brady \& R. Paul (Eds.), Robotics research 1 (pp. 215-224). Cambridge, MA.: MIT Press.

Morin, A. (2006). Levels of consciousness and self-awareness: A comparison and integration of various neurocognitive views. Consciousness and Cognition, 15, 358-371.

Nagel, T. (1974). What is it like to be a bat? The Philosophical Review, 83(4), 435-450. Navalpakkam, V., Arbib, M., \& Itti, L. (2005). Attention and scene understanding. In L. Itti, G. Rees, \& J. K. Tsotsos (Eds.), Neurobiology of attention (pp. 197-203). New York: Academic Press.

Oades, R. D., \& Isaacson, R. L. (1978). The development of food search behavior by rats: The effects of hippocampal damage and haloperidol. Behavioral Biology, 24(3), 327-337.

Parnas, M., Lin, A. C., Huetteroth, W., \& Miesenböck, G. (2013). Odor discrimination in Drosophila: from neural population codes to behavior. Neuron, 79, 932-944.

Parvizi, J., \& Damasio, A. (2001). Consciousness and the brainstem. Cognition, 79, 135-159.

Paulk, A. C., Stacey, J. A., Pearson, T. W. J., Taylor, G. J., Moore, R. J. D., Srinivasan, M. V., \& van Swinderen, B. (2014). Selective attention in the honeybee optic lobes precedes behavioral choices. Proceedings of the National Academy of Science of the United States of America, 111, 5006-5011.

Pelizzon, A., \& Gagliano, M. (2015). The sentience of plants: animal rights and rights of nature intersecting? Australian Animal Protection Law Journal, 11, 5-14.

Penfield, W., \& Jasper, H. (1954). Epilepsy and the functional anatomy of the brain. London: J. \& A. Churchill, Ltd.

Penfield, W., \& Rasmussen, T. (1950). The cerebral cortex of man: a clinical study of localization of function. New York: Macmillan.

Perry, C. J., \& Barron, A. B. (2013). Neural mechanisms of reward in insects. Annual Review of Entomology, 58, 543-562.

Petie, R., Garm, A., \& Nilsson, D.-E. (2011). Visual control of steering in the box jellyfish Tripedalia cystophora. Journal of Experimental Biology, 214, 2809-2815.

Pfeiffer, K. J., \& Crailsheim, K. (1998). Drifting of honeybees. Insectes Sociaux, 45, 151-167.

Pfeiffer, K., \& Homberg, U. (2014). Organization and functional roles of the central complex in the insect brain. Annual Review of Entomology, 59, 165-184.

Philippi, C. L., Feinstein, J. S., Khalsa, S. S., Damasio, A., Tranel, D., Landini, G., Williford, K., \& Rudrauf, D. (2012). Preserved self-Awareness following extensive bilateral brain damage to the insula, anterior cingulate, and medial prefrontal cortices. PLOS ONE, 7(8), e3841.

Plath, J. A., \& Barron, A. B. (2015). Current progress in understanding the functions of the insect central complex. Current Opinion in Insect Science, 12, 11-18.

Redgrave, P., Prescott, T. J., \& Gurney, K. N. (1999). The basal ganglia: a vertebrate solution to the selection problem?. Neuroscience, 89, 1009-1023.

Rosenthal, D. M. (2005). Consciousness and mind. New York: Oxford University Press.

Rosner, R., \& Homberg, U. (2013). Widespread sensitivity to looming stimuli and small moving objects in the central complex of an insect brain. Journal of Neuroscience, 33, 8122-8133.

Sareen, P., Wolf, R., \& Heisenberg, M. (2011). Attracting the attention of a fly. Proceedings of the National Academy of Science of the United States of America, 108(17), 7230-7235. 
Schiff, N. D. (2010). Recovery of consciousness after brain injury: a mesocircuit hypothesis. Trends in Neurosciences, 33(1), 1-9.

Schwaerzel, M., Monastirioti, M., Scholz, H., Friggi-Grelin, F., Birman, S., \& Heisenberg, M. (2003). Dopamine and octopamine differentiate between aversive and appetitive olfactory memories in Drosophila. Journal of Neuroscience, 23, 10495-10502.

Seeley, T. D. (1995). The wisdom of the hive. Cambridge: Harvard University Press.

Seelig, J. D., \& Jayaraman, V. (2013). Feature detection and orientation tuning in the Drosophila central complex. Nature, 503, 262-266.

Seelig, J. D., \& Jayaraman, V. (2015). Neural dynamics for landmark orientation and angular path integration. Nature, 521, 186-191.

Shu, D.-G., Conway Morris, S., Han, J., Zhang, Z.-F., Yasui, K., Janvier, P., Chen, L., Zhang, X.-L., Liu, J.-N., Li, Y., \& Liu, H.-Q. (2003). Head and back bone of the Early Cambrian vertebrate Haikouichthys. Nature, 421, 526-529. doi: 10.1038/nature01264

Skorupski, P., \& Chittka, L. (2006). Animal cognition: an insect's sense of time? Current Biology, 16(19), R851-R853.

Søvik, E., Perry, C. J., \& Barron, A. B. (2015). Insect reward systems: comparing flies and bees. In A. Zayed \& C. Kent (Eds.), Genomics, physiology and behaviour of social insects (Vol. 48, pp. 189-226). London: Academic Press

Sparks, D. L. (1988). Neuronal cartography: Sensory and motor maps in the superior colliculus. Brain, Behavior and Evolution, 31, 49-56.

Sprague, J. M. (1966). Interaction of cortex and superior colliculus in mediation of visually guided behavior in the cat. Science, 153(3743), 1544-1547.

Stephenson-Jones, M., Samuelsson, E., Ericsson, J., Robertson, B., \& Grillner, S. (2011). Evolutionary conservation of the basal ganglia as a common vertebrate mechanism for action selection. Current Biology, 21, 1081-1091.

Strausfeld, N. J. (1976). Atlas of an insect brain. Berlin: Springer-Verlag.

Strausfeld, N. J. (2012). Arthropod brains: Evolution, functional elegance, and historical significance. Cambridge, MA: Belknap Press.

Strausfeld, N. J., \& Hirth, J. (2013). Deep homology of arthropod central complex and vertebrate basal ganglia. Science, 340, 157-161.

Strawson, G. (2006). Realistic monism: Why physicalism entails panpsychism. Journal of Consciousness Studies, 13(10/11), 3-31.

Strube-Bloss, M. F., Nawrot, M. P., \& Menzel, R. (2011). Mushroom body output neurons encode odor-reward associations. The Journal of Neuroscience: The Official Journal of the Society for Neuroscience, 31(8), 3129-3140. doi: 10.1523/jneurosci.2583-10.201

Swanson, L. W. (2000). Cerebral hemisphere regulation of motivated behavior. Brain Research, 886, 113-164.

Tononi, G. (2004). An information integration theory of consciousness. BMC Neuroscience, $5(42)$.

Tononi, G. (2008). Consciousness as integrated information: a provisional manifesto. The Biological Bulletin, 215(3), 216-242.

Tononi, G., \& Koch, C. (2015). Consciousness: here, there and everywhere? Philosophical Transactions of the Royal Society B, 370(1668). doi:10.1098/rstb.2014.0167

Trestman, M. (2013). The Cambrian explosion and the origins of embodied cognition. Biological Theory, 8, 80-92.

Van Opstal, A. J., Hepp, K., Suzuki, Y., \& Henn, V. (1995). Influence of eye position on activity in monkey superior colliculus. Journal of Neurophysiology, 74, 1539-1610.

Van Swinderen, B. (2005). The remote roots of consciousness in fruit-fly selective attention? BioEssays, 27, 321-330.

Van Swinderen, B., \& Greenspan, R. J. (2003). Salience modulates 20-30 Hz brain activity in Drosophila. Nature Neuroscience, 6, 579-586. 
Von Holst, E., \& Mittelstaedt, H. (1950). Das reafferenzprincip (wechselwirkungen zwischen zentralnervensystem und peripherie). Naturwissenschaften, 37, 464-476.

Webb, B. (2004). Neural mechanisms for prediction: do insects have forward models? Trends in Neurosciences, 27, 278-282.

Webb, B. (2006). Transformation, encoding and representation. Current Biology, 16(6), R18.

Wehner, R. (2013). Life as a cataglyphologist - and beyond. Annual Review of Entomology, 58, 1-18.

Weir, P. T., Schnell, B., \& Dickinson, M. H. (2014). Central complex neurons exhibit behaviorally gated responses to visual motion in Drosophila. Journal of Neurophysiology, 111, 62-71.

Wimsatt, W. C. (2007). Re-engineering philosophy for limited beings: piecewise approximations to reality. Cambridge: Harvard University Press.

Zenon, A., \& Krauzlis, R. J. (2012). Attention deficits without cortical neuronal deficits. Nature, 489, 434-437.

Zompa, I. C., \& Dubuc, R. (1996). A mesencephalic relay for visual inputs to reticulospinal neurones in lampreys. Brain Research, 718, 221-227.

Zompa, I. C., \& Dubuc, R. (1998). Electrophysiological and neuropharmacological study of tectoreticular pathways in lampreys. Brain Research, 804, 238-252.

Call for Commentary: Animal Sentience publishes Open Peer Commentary on all accepted target articles. Target articles are peer-reviewed. Commentaries are editorially reviewed. There are submitted commentaries as well as invited commentaries. Commentaries appear as soon as they have been revised and accepted. Target article authors may respond to their commentaries individually or in a joint response to multiple commentaries.

Instructions: http://animalstudiesrepository.org/animsent/guidelines.html 
Call for Commentary: Animal Sentience publishes Open Peer Commentary on all accepted target articles. Target articles are peer-reviewed. Commentaries are editorially reviewed. There are submitted commentaries as well as invited commentaries. Commentaries appear as soon as they have been revised and accepted. Target article authors may respond to their commentaries individually or in a joint response to multiple commentaries.

Instructions: http://animalstudiesrepository.org/animsent/guidelines.html

\title{
Why fish do not feel pain
}

\author{
Brian Key \\ Biomedical Sciences \\ University of Queensland \\ Australia
}

\begin{abstract}
Only humans can report feeling pain. In contrast, pain in animals is typically inferred on the basis of nonverbal behaviour. Unfortunately, these behavioural data can be problematic when the reliability and validity of the behavioural tests are questionable. The thesis proposed here is based on the bioengineering principle that structure determines function. Basic functional homologies can be mapped to structural homologies across a broad spectrum of vertebrate species. For example, olfaction depends on olfactory glomeruli in the olfactory bulbs of the forebrain, visual orientation responses depend on the laminated optic tectum in the midbrain, and locomotion depends on pattern generators in the spinal cord throughout vertebrate phylogeny, from fish to humans. Here I delineate the region of the human brain that is directly responsible for feeling painful stimuli. The principal structural features of this region are identified and then used as biomarkers to infer whether fish are, at least, anatomically capable of feeling pain. Using this strategy, I conclude that fish lack the necessary neurocytoarchitecture, microcircuitry, and structural connectivity for the neural processing required for feeling pain.
\end{abstract}

Keywords: pain, fish, consciousness, feeling, noxious stimuli, cortex, awareness, qualia

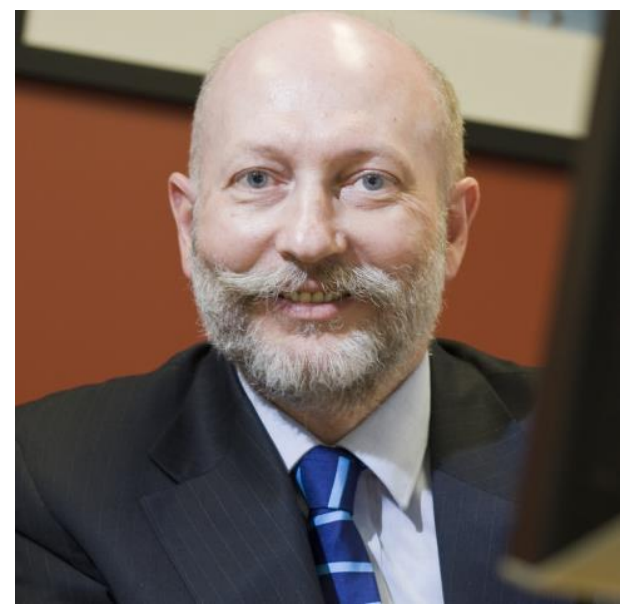

Brian Key brian.key@uq.edu.au is Head of the Brain Growth and Regeneration Lab at the University of Queensland, dedicated to understanding the principles of stem cell biology, differentiation, axon guidance, plasticity, regeneration and development of the brain.

Address: School of Biomedical Sciences, University of Queensland, Brisbane 4072, Australia http://www.uq.edu.au/sbms/staff/brian-key

\section{Introduction}


"Qualia" are the subjective or phenomenal (conscious) experiences associated with the perception of olfactory, taste, visual, auditory, and somatosensory stimuli. Qualia are often described as the "what it feels like" when we perceive our environment (Nagel, 1974; Kanai and Tsuchiya, 2012). The salient element of a quale is that the experience is conscious, and it is hence dependent on conscious neural processing (Rolls, 2007; Keller, 2014). The distinction between conscious and non-conscious processing of stimuli is clearly recognised in the case of pain. The non-conscious neural processing of noxious stimuli (i.e., those stimuli that cause or have the potential to cause body tissue damage) is referred to as nociception. The resultant motor behaviours (such as the flexion withdrawal reflex; e.g., withdrawing a hand from a hot stove) are called nocifensive behaviours and are executed non-consciously. The feeling of pain in humans may subsequently emerge at longer latency, since it involves supraspinal neural pathways leading to evoked cerebral potentials (Garcia-Larrea et al., 1993; Bromm and Lorenz, 1998) that are associated with conscious neural processing (Boly et al., 2011; Changeux, 2012; Constant and Sabourdin, 2015).

Not all noxious stimuli necessarily cause pain. For instance, activation of inhibitory neural circuitry can prevent the subsequent conscious processing of noxious stimuli (Millan, 2002), or alternatively an individual may have damaged neural circuitry that prevents the conscious processing of such signals. Moreover, some vertebrates, such as fish, may lack the neural machinery or architecture to consciously experience (i.e., to feel) noxious stimuli as painful (Key, 2015a). The possibility that fish lack the necessary neural "hardware" to feel pain is typically overlooked because of anthropomorphic tendencies that bias interpretations of behavioural observations (Horowitz and Bekoff, 2007). Given this controversy, an alternate view is emerging. The proposition is that it is impossible to ever know what a fish feels, and as a consequence fish should be given the "benefit of the doubt" and unconditionally bestowed with the ability to feel pain.

The argument that no one can ever know what a fish feels because they can never be a fish is similar to issues raised in Nagel's (1974) classic philosophical essay regarding what it feels like to be a bat. While on one hand it is easy to accept that we can never be a fish, on the other hand we vicariously experience the pain of our friends and family members without ever really knowing what they actually feel (Meyer et al., 2012). We most likely do this because we intuitively understand that humans share similar functioning nervous systems and behaviours and therefore will experience similar feelings. Although we will never be fish, I contend that we can strongly defend the thesis that fish do not feel pain based on inferences derived, in this case, from experimental evidence from neuroscience and evolutionary biology investigations on humans and nonhuman animals. Similar strategies are adopted extensively in biological research. They have been particularly successful in better understanding, for example, the evolution of feathers and flight from dinosaurs to birds (Xu et al., 2014), the role of gene regulatory pathways in animal body plans (Davidson and Erwin, 2006) and the underlying conservation of neural circuitry controlling locomotor behaviour throughout vertebrate phylogeny (Goulding, 2009).

The idea that it is more benevolent to assume that fish feel pain, rather than not feel pain, has emerged as one position of compromise in the debate on fish consciousness. However, accepting such an assumption at "face value" in biology can lead to devastating consequences. I would like to highlight this concept using the recent example of how a scientific research article was published that purportedly linked measles-mumps-rubella (MMR) vaccination causally to autism. Although this link was subsequently disproven, 
many people continued to accept at "face value" the causal association between MMR vaccination and the development of autism in children (Brown et al., 2012). This caused parents not to have their children vaccinated, and it subsequently led to a public health crisis (Flaherty, 2011). Thus, while initially accepting the idea that MMR vaccination causes autism may be considered a safe way to proceed (even if it is not true), it can cause catastrophic effects.

Accepting at "face value" that fish feel pain may seem like a harmless alternative, but it has led to inappropriate approaches to fish welfare (Arlinghaus et al., 2007; Diggles et al., 2011). It could also lead to legislative restrictions on fish-related activities with potentially serious negative implications for native subsistence fishing (Capistrano and Charles, 2012), human nutrition and food supply (Tacon and Metian, 2013), and economic development (Tveteras et al., 2012). It should be noted that the "benefit of the doubt" argument can quickly lead to unsupported anthropomorphic conclusions, such as believing fish either feel happy being in company of other fish, or they feel disappointed when they fail to capture prey.

While there is no convincing scientific evidence for the ability of fish to feel pain (Key, 2015a; Rose et al., 2014), absence of evidence for pain does not mean evidence of absence of pain. (I will return to this issue again.) Therefore, I will present some of the reasoning, based on neuroscience and evolutionary biology principles, for why it is highly improbable that fish feel pain. I will frame my argument around three basics questions associated with the where, what and why of pain. That is, where does pain arise in the nervous system, what is the cellular architecture associated with the where of pain, and finally why do the where and what give rise to pain. Once I have outlined these three fundamental premises, I will argue that fish lack the necessary neuroanatomical structures or neural circuits to perform neural processing necessary for feeling pain.

\section{Defining the Fundamental Premises of the Argument}

Pain is in the brain. The premise that pain is generated by neural processing in the brain is important for appreciating that select neural architectures (i.e., arrangements of pools or clusters of neurons) and circuits (connections between these clusters) are necessary to feel pain. When a noxious stimulus is applied to the toes, it may seem like the resultant pain is localised in these appendages, however, the feeling of pain is actually generated in the brain. One line of evidence supporting this conclusion comes from paraplegic individuals with a complete spinal cord lesion. Such a lesion prevents the relay of neural information from the toes to the brain. These people no longer feel pain or any sensation applied to the body below the level of their lesions.

Whereas it may seem straightforward that the isolated spinal cord or any other similar neural tissue that generates simple reflexes is unlikely to feel pain, problems begin to emerge when we try to distinguish between simple reflexes (knee-jerk reflex), integrated reflexes (e.g., crossed extension reflex; Sherrington, 1910) and more complex movements such as scratching and locomotion that involve reconfiguration of reflex circuitry into local patterns generators (Frigon, 2012). For example, a spinal-lesioned dog (a dog with a spinal cord injury that severs passage of neural signals between the spinal cord and brain, which is similar to the condition of paraplegia in humans) will attempt to scratch a piece of paper soaked in an irritant (acetic acid) from its body. This behaviour involves a complex coordination of hip, knee and ankle joint movements that are not stereotyped since joint kinematics vary as the paper is shifted to different parts of the body. Furthermore, a spinal-lesioned rat or mouse is able to learn to position its limb 
above a dish of water in order to prevent delivery of an electric shock when the limb touches the water (Crown et al., 2002; Jindrich et al., 2009; Grau, 2014).

One interpretation of these behaviours is that the spinal cord (independently of the brain) is able to feel the shock of the electric current and hence the animal is motivated to move its limb into a position that prevents it from being shocked. However, we know from human experience that there are no sensations in the body below the level of the spinal cord lesion. The reason the spinal cord and its connections to skin and muscle elicit such motor behaviours (referred to as nocifensive behaviours) is because it has evolved over hundreds of millions of years to facilitate survival of the organism, and not because it has feelings or possesses any inner motivation to act. Consequently, using nocifensive behaviours as evidence of feeling of pain is fraught with problems of misinterpretation.

In order to begin to address whether fish can feel pain, I propose that it is necessary to first understand the neural basis of pain in humans, since it is the only species able to directly report on its feelings. The strategy adopted here involves three steps: (1) identify which brain region is directly responsible for the feeling of pain in humans; (2) define the neuroanatomical features of this region that allow the neural processing that generates felt pain; and (3) assess whether fish have similar structural features that can then be used to make inferences about whether fish can, or cannot, feel pain. Although this approach is straightforward, the literature involving human pain, conscious neural processing, and structure-function relationships across phylogeny is plagued by dogmatic preconceptions and conceptual misunderstandings. Consequently, what may appear sensible to some, will arouse claims of bias from others. Nonetheless, I have attempted to initially provide a comprehensive overview of the origins of human pain in the brain. In doing so, I hope to dispel some misunderstandings that commonly emerge in the literature about pain in fish because of perfunctory attention to the neuroscience of pain.

There is compelling evidence that pain in humans is generated by neural activity in the cerebral cortex, a thin, multi-layered plate of neuronal cell bodies and synaptic connections that folds on itself to form sulci (furrows) and gyri (ridges) as it forms the surface of the anterior brain. The cortex is anatomically defined by a number of distinct lobes (e.g., frontal, occipital, temporal, insular and parietal), and each of these lobes is further subdivided on the basis of anatomical cytoarchitecture and functional properties. While subcortical structures (e.g., basal ganglia, ventral telencephalic nuclei, thalamus, midbrain and hindbrain) contribute to the processing of noxious stimuli and to nocifensive behaviours, the feeling of pain arises in the cortex. There are at least three principal lines of evidence supporting the cortical origins of human pain: (1) brain imaging reveals a dynamic network of cortical activity that provides a neural signature of pain; (2) lesions to cortical regions in this network perturb pain; and (3) direct stimulation of cortical regions in this network evoke pain.

Core network of cortical activity during pain. There is a dynamic core of cortical regions (including prefrontal cortex, anterior cingulate cortex, somatosensory areas I [SI] and II [SII], and the insular cortex) that consistently becomes active during the experience of pain in humans (Schnitzler and Ploner, 2000; Tracey and Mantyh, 2007; Moayedi, 2014; Mano and Seymour, 2015). This neural signature, as determined by functional magnetic resonance imaging, is sufficiently accurate that it can be captured in an algorthm and used to predict whether a human subject is experiencing pain (Wager et al., 2013; Rosa and Seymour, 2014). None of the cortical subregions in this neural signature are selectively active only during pain (Iannetti and Mouraux, 2010), but rather it is the overall dynamic 
and fluid activity of the network that defines the subjective experience (Garcia-Larrea and Peyron, 2013; Kucyi and Davis, 2015).

Segerdahl et al. (2015) have recently used arterial spin-labelling quantitative perfusion imaging to quantify cortical neural activity. They demonstrated a specific role of the dorsal-posterior insular cortex in pain sensation. The subjective intensity of pain correlated positively only with neural activity in this cortical region. The insular cortex is grossly partitioned into anterior, middle and posterior divisions, and each of these regions is selectively interconnected as well as connected with other brain regions associated with the dynamic pain network (Weich et al., 2014). Together, these results suggest that the insular cortex plays an important integrative function in the neural processing associated with the sensation of pain and other salient stimuli (Uddin, 2015).

Typically there is no simple relationship between the evoked potential amplitude recorded by electroencephalography in cortical regions and either the intensity of the pain stimulus or the magnitude of the pain sensation (Iannetti et al., 2008). Instead, the strength of high frequency gamma oscillations within SI correlates positively with both the intensity of the stimulus (Rossiter et al., 2013) and the intensity of the pain (independent of the salience of the stimulus) (Zhang et al., 2012). These observations have led some authors who initially challenged the idea of a cortical signature of pain (Mouraux et al., 2011) to now embrace the idea that gamma oscillations in discrete cortical regions encode pain (Zhang et al., 2012). The putative role of gamma oscillations in pain is exciting given that local cortical synchrony (Gray et al., 1989; Gross et al., 2007; Tiemann et al., 2010), and long-range synchrony or binding of gamma oscillations, have been consistently proposed to underlie pain and other feelings (Gray and Singer, 1989; Engel et al., 1991; Engel and Singer, 2001; Salinas and Sejnowski, 2001; Fries et al., 2007; Hauck et al., 2007; Gregoriou et al., 2009; Fries, 2009; Hauck et al., 2009; Ploner et al., 2009; Hipp et al., 2011; Singer, 2011; Nikolic et al., 2013; Buzsaki and Schomburg, 2015).

Gamma oscillations arise from the interplay between inhibitory and excitatory neurons in the circuitry of the cortex (Tiesinga and Sejnowski, 2009). While many regions of the nervous system across many different species display local gamma oscillations (Bosman et al., 2014), it is the synchronization of gamma oscillations between specific and distal cortical regions via recurrent connections that uniquely defines the quality of the feelings correlated with them (Orpwood, 2013). It is not yet known how these selfregulatory oscillations may generate the pain sensation; however, strong functional interconnectivity between discrete cortical regions is essential for pain.

A cortical neural signature of human pain is consistent with recent observations that the resting state of the conscious brain is defined by a dynamic spatiotemporal network of cortically active areas (Barttfeld et al., 2015). While the activity level of this network fluctuates transiently, there is a hub of activity that emerges over longer time frames that provides a unique signature of the resting state. General cortical activity, cortical binding by synchrony and convergence, and the dynamic exploration of connectivity across this network all diminish under anaesthesia, as awareness is lost (Mashour, 2013; Barttfeld et al., 2015). This cortical response to anaesthesia is similar to the analgesia-mediated reductions in activity of the cortical regions associated with pain (Wager et al., 2013).

Despite the fact that rats and mice last shared a common ancestor with humans 90 million years ago (Hedges, 2002), these rodents still possess a cortex (albeit a smooth rather than a folded one) as well as many cortical regions homologous to those in humans. Despite their phylogenetic separation, rats also exhibit a network of neural activity involving cortical regions similar to those of humans when humans are exposed to stimuli 
that cause pain (Thompson and Bushnell, 2012). The evolutionary conservation of this cortical pain signature further supports the idea that the cortex plays a significant role in the sensation of pain throughout vertebrate phylogeny. This conservation of function is further supported by experimental studies that indicate a causal role of the cortex in pain.

Core network of cortical activity during pain. Identifying cortical regions that become active during pain is merely correlative, and while they may be beneficial as biomarkers for pain, they do not provide insight into the underlying causal basis of pain. The activity in these cortical regions needs to be experimentally manipulated in order to begin to understand their role in pain. While experimentally manipulating brain activity in humans has ethical implications, considerable insight has been obtained by examining the effects of physical lesions to cortical regions as a result of stroke, tumours or brain surgery. Overall, this approach has provided strong support for the causal role of specific cortical regions in human pain (Biemond, 1956; Berthier et al., 1988; Ploner et al., 1999; Veldhuijzen et al., 2010; Garcia-Larrea, 2012a and 2012b; Vierck et al., 2013).

Lesion analyses reveal that the insular cortex is one of the core components of the network of cortical regions that underlie the sensation of pain. Early studies revealed that lesions to the operculo-insular cortex either caused or resulted in the loss of pain depending on their location and severity (Biemond, 1956). The parietal operculum is the cortical region that is adjacent to the insular cortex and contains SII, another core component of the neural signature of pain. Lesions to the operculo-insular cortex can also cause central pain syndrome (pain in the absence of peripheral noxious stimuli; GarciaLarrea, 2012a and 2012b). It should be noted that not all insular lesions alter pain sensation or produce the same symptoms: the site and size of the lesion and associated damage outside the region also tend to influence clinical outcome (Bassetti et al., 1993; Greenspan et al., 1999; Starr et al., 2009; Garcia-Larrea 2012b; Veldhuijzen et al., 2010; Baier et al., 2014).

The role of SI in pain has been conclusively demonstrated by numerous clinical studies of lesions (Cerrato et al., 2005; Vierck et al., 2013). Focal lesions to SI cause sensory loss of pain in discrete regions of the body and indicate that this cortical region is indeed necessary to feel pain (Cerrato et al., 2005). However, both the lesion location and the extent of the lesion also clearly influence the resulting symptoms experienced by the patient. Vierck et al. (2013) highlighted how partial ablations of SI (that do not remove the 3a subregion) can lead to only temporary deficiency in the feeling of pain. Removal of both areas $3 a$ and $3 b / 1$ of SI is required for complete permanent loss of pain (Vierck et al., 2013). SI is considered to be involved principally in the spatial localisation of pain and is perhaps only indirectly responsible for pain sensation by conveying neural activity to other cortical regions (Laureys, 2005; Neirhaus et al., 2015). Nonetheless, SI is clearly necessary for pain, and its role in the neural signature of pain further confirms the cortical origins of pain.

Examining the effects of cortical lesions arising from tumours and stroke on human pain is difficult since lesion size and location produces considerable variability in clinical symptoms (Berthier et al., 1988). However, discrete chemical lesions to specific cortical regions can easily be executed and verified in rats, where they have been used to demonstrate the roles of both the anterior cingulate (Johansen et al., 2001; Qu et al., 2011) and insular cortices (Benison et al., 2011; Coffeen et al., 2011) in pain. These experimental studies are beginning to reveal the phylogenetic conservation of a select network of cortical regions in pain from rodents to humans. 
Stimulation of the cortex elicits pain. Direct electrical stimulation of the cortex in awake patients undergoing brain surgery has provided direct evidence for a causal role of the cortex in human pain. This approach was pioneered by Wilder Penfield and initially involved the use of surface electrodes to map the function of specific cortical regions during brain surgery. Later studies progressed to the use of intracortical depth electrodes and then, more recently, implantable electrodes that are activated after surgery (Selimbeyoglu and Parvizi, 2010). Penfield found that it was typically difficult to elicit sensations by direct stimulation of the cortex (Penfield and Perot, 1963). These results were most likely related to the complex dynamics of neural activity in the cortex required for pain and to limitations of accessibility of cortical regions to surface electrodes.

Similar difficulties in perceiving complex visual images have been reported following stimulation of the visual cortices (Lee et al., 2000). Only $\sim 5 \%$ of all electrode placements elicit complex visual scenes such as faces. Nonetheless, patients did sometimes perceive the feeling of pain when the temporal cortex was stimulated. Patients were known to exclaim "pain in my forehead" or "I had a little pain in my forehead" (Penfield and Perot, 1963). When the insular cortex was stimulated, some patients reported visceral sensations such as pain, nausea and scratching (Penfield and Faulk, 1955). Most often the somatic sensations were described as "tingling," "shock," "numbness," or "tightness." The role of the insular cortex in producing human pain has subsequently been repeatedly confirmed by numerous clinical studies involving direct electrical stimulation (Ostrowsky et al., 2002; Duffau et al., 2006; Afif et al., 2008; Mazzola et al., 2009; Stephani et al., 2011; Afif et al., 2012; Mazzola et al., 2012; Mazzola et al., 2014). In addition, non-invasive stimulation of the cortex using transcranial magnetic stimulation has revealed roles of SII in encoding pain intensity (Lockwood et al., 2013) and SI in pain localization (Porro et al., 2007).

Rodent studies have begun to provide new insight into the cell and molecular bases of pain using modern genetic tools (Daou et al., 2013). Gu et al. (2015) selectively activated inhibitory neural circuitry in the anterior cingulate cortex using optogenetic stimulation and found overall reduced neural activity in this cortical region was associated with reduced pain. Neuropathic pain in a mouse model has been shown to be associated with synaptic plasticity in the insular cortex (Qui et al., 2014). Specifically this plasticity was caused by long-term increases in the amount of synaptic N-methyl-Dasparate receptor (NMDAR) in the insular cortex. Subsequent mouse knock-in experiments also revealed that increased expression of the AMPA receptor in the insular cortex was responsible for long-term potentiation of glutamate transmission during neuropathic pain (Qui et al., 2014). Together, these observations suggest that inhibiting glutamate receptor function in the cortex could have therapeutic value in pain. In summary, there is now strong evidence from human clinical investigations and rodent experimentation that there is a network of cortical regions that plays a causal role in pain.

Putative evidence presented as contrary to cortical localization of pain. There are two lines of evidence that superficially appear to be inconsistent with the conclusion that pain arises in the cortex. This evidence has been used to argue that pain is generated in the lower, and phylogenetically older, regions of the brain, such as the brainstem. First, there are clinical reports of children lacking much of their cerebral cortices who seem to display behaviours that would suggest being able to feel; and second, there are adults with pathological lesions in which much of their insular cortex has been ablated and yet they still feel pain. However, more careful examination of these reports as well as other clinical 
case studies indicates that these two lines of evidence are inadequate and do not invalidate claims that the cortex is responsible for pain.

Examination of four rare cases of children born with near-complete absence of the cerebral cortex (i.e., hydranencephaly) revealed that they displayed a variable mix of motor behaviours such as smiling, giggling, heads turning to sound, and visual fixation and tracking of objects (Shewmon et al., 1999; Werth, 2007). On the basis of these observations, it has been concluded that consciousness and feelings (such as visual qualia and pain) are independent of the cerebral cortex and arise at the level of the brainstem (Panksepp, 2011; Damasio and Carvalho, 2013). However, in contrast to these specific case studies, most hydranencephalic children are moribund (Barnet et al., 1966) and visually blind (Hill et al., 1961; Werth, 2008). In fact, most individuals with this syndrome die in utero or within weeks of birth (Pavone et al., 2014; Short and Kardan, 2014). Patients who survive longer are typically in vegetative states, and hence unaware of their environments, and have spastic quadriparesis (McAbee et al., 2000; Rados et al., 2014). What needs to be appreciated is that heterogeneity in behavioural phenotypes arises from an underlying heterogeneity in the severity of neuroanatomical deficiencies in these children (Barnet et al., 1966; Aylward et al., 1978; Shewmon et al., 1999; Werth, 2007). Typically, most of these children still possess some cerebral cortex, suggesting that those with more overt behaviours could have more functional cortical tissue. A recent review of the literature has revealed that $70 \%$ of hydraencephalics have occipital lobe remnants and $40 \%$ have frontobasal lobe remnants (Cecchetto et al., 2013). Consequently, it is difficult to relate function to the cortex in these children without very detailed neuroanatomical and physiological analyses.

Concluding that the cortex does not produce feelings (i.e., pain) because that function remains when the cortex is purportedly ablated requires, at the very least, that the cortex be totally ablated. This need for ensuring complete loss of a brain region is highlighted by experiments in the rodent olfactory system. The olfactory nerve fibres from the nose project into the brain and terminate in synaptic glomeruli in the olfactory bulb. In order to assess the ability of animals to smell without an olfactory bulb, this structure was physically removed by surgery. However, when small fragments of the bulbs were left intact $(\sim 20 \%$ glomeruli were present), animals discriminated between odorants similarly to sham-operated controls (Lu and Slotnick, 1998). These results demonstrate that even small rudiments of brain regions can perform remarkable functions, and they illustrate the importance of not over-interpreting the significance of behaviours in hydranencephalic children when lesions are not complete. The conclusion that feelings are perceived subcortically (Panksepp, 2011; Damasio and Carvalho, 2013) then becomes questionable, especially when it is based upon observations of a heterogenous and small population of hydranencephalic children who do not completely lack cerebral cortices (Shewmon et al., 1999). It is interesting that Shewmon et al. (1999) actually noted the difficulty in extrapolating from their observations and merely suggested that these children should be given the "benefit of the doubt" with respect to awareness.

Putting aside the problems associated with lesion heterogeneity, it is well known that the visuomotor behaviours reported in congenitally decorticate children by Shewmon et al. (1999) are reflexively controlled by the mid- and hind-brain and are not signs of conscious neural processing (Pasik et al., 1969; Dalby et al., 1970; Ferrier and Cooper, 1976). For instance, these children exhibited visual saccades to an object (e.g., mother's face) that suddenly appeared in their visual fields, and were then able to remain fixated on the object. Experiments in monkeys have shown that the midbrain retinotectal pathway guides the saccades to the object even after the visual cortex is ablated (Kato et 
al., 2011). These results strongly demonstrate that monkeys are able to locate objects in their environment in the absence of visual consciousness (Stoerig, 2001; Silvanto, 2014). Recently it was shown that the superior colliculi in monkeys respond rapidly to face and face-like stimuli (Nguyen et al., 2014). The subsequent maintenance of the gaze on an object is called fixation and is also executed subcortically (without awareness) by bilateral activation of the superior colliculi (Goffart et al., 2012). Given that mammalian conscious vision occurs in the cortex, the visual behaviours in hydranencephalic children (provided they truly lack cortical tissue) must occur non-consciously, mediated by the midbrain superior colliculus.

The idea that the brainstem is the origin of emotional feelings such as pain, as proposed by Panksepp and Damasio (Panksepp, 2011; Damasio and Carvalho, 2013), is further weakened from observations in patients with analgetic thalamic syndrome. These individuals have hemiparesis and sensory loss on the contralateral side to a thalamic infarct and exhibit an absence of evoked potentials in the somatosensory cortex in response to painful stimuli (Maugiere and Desmedt, 1988; Wessel et al., 1994). Thus, the transmission of neural activity associated with painful stimuli is blocked from reaching the primary somatosensory cortex (SI). This loss of cortical connectivity causes loss of pain sensation. These results demonstrate that pain is not generated by either brainstem or subcortical structures since these structures remain intact in these patients. These patients also have normal subcortical (non-thalamic) pathways to the cortex that would allow reporting of sensations. These results are also consistent with the loss of pain that occurs following localised cortical infarcts that preserve brainstem and subcortical pathways. Consequently, suggesting that pain is generated subcortically, or in the brainstem, and that its associated neural activity only reaches the cortex to subserve other functions is not consistent with available evidence (Devor et al., 2014).

The extrapolation that hydranencepahlic children feel emotions subcortically because they smile, giggle or laugh (Panksepp, 2011; Damasio and Carvalho, 2013) is also unfounded, as these motor behaviours can be executed involuntarily by innate reflex pathways in the brainstem as well as voluntarily by the cortex. For instance, patients with focal infarcts of the brain stem do not smile involuntarily in response to emotional stimuli (Cerrato et al., 2003). However, these patients have no problems smiling voluntarily (Cerrato et al., 2003). This syndrome is referred to as "emotional facial paresis." Reflexive smiling is controlled by the medulla in the brainstem, whereas voluntary smiling is dependent on an intact pyramidal pathway from the motor cortex. The importance of distinguishing between instinctive behaviours generated by the brainstem and felt emotions generated by the cortex has been previously discussed extensively (LeDoux, 2012; LeDoux, 2013; LeDoux, 2014a; LeDoux, 2014b; Rolls, 2014a; Rolls, 2014b; Scott, 2014).

As indicated above, the second line of evidence that has been used to suggest that the cortex is not responsible for feelings comes from observations of a single human patient who continued to feel pain, despite extensive bilateral damage to the insular cortex as well as more modest lesions to various other brain regions (Damasio et al., 2012; Damasio and Carvalho, 2013). Given that the insular cortex is a central part of the cortical neural signature of pain, it has been suggested that the insular cortex is therefore not essential for pain and that feelings arise subcortically, most likely in the brainstem (Damasio and Carvalho, 2013). This conclusion was based on observations of a single patient without quantitative sensory testing or functional magnetic imaging of the lesioned brain during sensory stimulation (Damasio et al., 2012). 
Despite extensive destruction of the insula, this patient could still perceive pain, and anecdotal evidence suggested the patient was perhaps overly sensitive to noxious stimuli. However, other cortical regions associated with pain such as SI, SII, portions of the cingulate cortex, and the dorsolateral frontal orbital cortex remained undamaged in this patient. Damasio et al. (2012) were reasonably circumspect in their discussion of this patient and did indicate that these regions may be sufficient to generate the feeling of pain. More recently, a second patient with extensive, but not complete, bilateral lesions of the insular cortex has also been reported to feel pain (Feinstein et al., 2015). Quantitative sensory testing revealed that this patient had a heightened sensitivity to pain, as suggested by the patient described by Damasio et al. (2012). Unfortunately, functional magnetic imaging was not conducted during pain in this patient (Feinstein et al., 2015). Imaging would have provided valuable insights into the plasticity of the cortical signature of pain.

The observations of the patients described by Damasio et al. (2012) and Feinstein et al. (2015) have to be placed within the context of other patients with cortical lesions. Berthier et al. (1988) described six patients who all had insular cortex lesions together with damage to various other cortical regions. These patients all exhibited asymbolia for pain, which involved a lack of appropriate withdrawal response and inadequate emotional response to painful stimuli applied anywhere over the body. These patients could all recognize a painful stimulus as painful but did not experience the unpleasant sensations associated with it. Clearly, specific cortical regions are essential for the unpleasantness of pain, but these regions are distinct from the ones responsible for the detection of a stimulus as painful.

These observations are consistent with the idea that the sensation of pain relies on multiple parallel pathways processing separate aspects of the stimulus, such as discriminative and affective components (Melzack, 1999). Interestingly, one of the patients described by Berthier et al. (1988) had a restricted lesion involving the posterior insular cortex and parietal operculum, suggesting that both of these regions are integral to feeling pain. Berthier et al. (1987) also described a patient who exhibited a total lack of pain unpleasantness on the left side of their body following a restricted lesion to the right insula and surrounding tissue. These observations suggest that the identification of a painful stimulus is not dependent upon the normally unpleasant feeling arising from the stimulus. It indicates that pain can be distinguished by the intensity and the nature (e.g., feeling of sharpness or dullness) of the stimulus without the need for the feeling of unpleasantness. Similar dissociation of submodalities of a stimulus has been reported in other sensory systems, such as hearing (Roeser and Daly, 1974).

An analysis of 24 patients with partial unilateral insular cortical lesions revealed quantitative increases in the pain thresholds for heat and cold (Baier et al., 2014). Starr et al. (2009) also reported that the pain threshold for heat on the lesioned side was markedly higher than the unlesioned side in one of two patients with extensive (but not complete) unilateral insular cortex lesions. The second patient reported not feeling pain on either side in response to cold stimuli, even at $0^{\circ} \mathrm{C}$. Interestingly, functional magnetic imaging of both patients revealed unusually high activity in SI ipsilateral to the side of the body receiving the noxious stimulus. These results suggest that the sensation of pain might have been affected by commissural connections.

It is very rare, and probably impossible, to identify patients who completely and selectively lack a single and specific brain region, such as the insular cortex. There is always collateral damage or partial remnants remaining that weaken inferences. When interpreting observations from these studies it is important to note that a structure such 
as the insular cortex has subdomains that can each exhibit different functions (Weich et al., 2014). Since some of these functions could facilitate pain while others may reduce pain, it is possible that loss of the whole structure and/or other cortical regions would not have the expected consequences as a focal lesion. Nonetheless, if we ignore these important issues, and instead assume that selective loss of the whole insular cortex is possible and that pain is not lost, what then does it reveal about the role of the insular cortex?

This observation merely informs us that the network of brain regions associated with pain can function when one, or more, of its nodes are lost. Computational modelling of cortical networks has already begun to reveal the extent of their resilience to targeted lesions (Alstott et al., 2009; Horwitz et al., 2013). Such redundancy is valuable in any complex system and is consistent with other biological processes such as gene regulation (Glassman, 1987). Gene regulatory networks involving multiple feedback and feedforward interactions can often continue to operate normally when one or more genes are ablated (Tschopp and Duboule, 2011; Zhang, 2012).

Pain involves conscious neural processing. Given that the cortex is both necessary and sufficient for the feeling of pain in humans, the question now becomes: what are the unique functional properties of the cortex that are responsible for pain? Since pain is the conscious (felt) neural processing of noxious stimuli, we should, in the first instance, be asking what are the defining properties of conscious processing in the human cortex. Conscious processing is dependent on at least two non-mutually exclusive processes: signal amplification and global integration across the surface of the cerebral cortex (Dehaene et al., 2014; Pritchett et al., 2015). Amplification provides a mechanism to increase signal-to-noise ratio and to produce ongoing neural activity after the initial sensory stimulus has ceased (Murphy and Miller, 2009).

Global integration ensures the propagation and sharing of neural information so that the most appropriate response is generated in the context of current and past experiences. Global integration has both temporal and spatial characteristics that allow neural activity to be filtered, summated, and averaged over time (temporal) and across cortical regions (space). This integration involves functional connectivity between distant cortical regions (exhibiting segregated local neural processing) (Park and Friston, 2013). Functional connectivity refers to temporally correlated neural activity (usually measured indirectly, such as by magnetic resonance imaging in humans) between specific regions across the cortical surface (Friston et al., 1993; Biswal et al., 1995).

Recently, the amount of information transferred across distant sites within the cortex has been quantified using electroencephalography. These quantitative values have been successfully used to distinguish between conscious, minimally-conscious and nonconscious patients (Casali et al., 2013; King et al., 2013; Sitt et al., 2014). With respect to sensory perception, Godwin et al. (2015) demonstrated that visual awareness of a simple, small, grey disc resulted in increased functional connectivity across broad regions of the cortex. Thus, global integration mediated by functional connectivity is a critical defining feature of conscious processing. Functional connectivity analyses of humans in response to thermal pain have revealed strong connectivity across a large brain network, including regions previously associated with the neural signature of pain, such as the insula, SI, SII, cingulate gyrus, and prefrontal cortex (Peltz et al., 2011). Thus, global integration is consistent with the dynamic neural signature of pain within the cortex. Computational analyses of functional magnetic resonance imaging signals have enabled the effective connectivity between cortical regions to be characterised (Zhan and Yu, 2015; Park and 
Friston, 2013). Effective connectivity provides a causal basis of integration across neuronal populations; it defines whether neural activity in one population of neurons causes activity in another population. Such methods are being used to decipher the causal propagation of neural activity through cortical regions during global cortical integration associated with pain (Liang et al., 2011; Kalberlah et al., 2013; Khoshnejad et al., 2014).

In summary, the cortex has come to be viewed in a hierarchical manner as segregated modules or communities (neuronal populations such as cortical subregions) where neuronal integration and amplification perform specific local functions (Sporns, 2013). These modules are interconnected in forming networks or hubs of activity that enable mesoscale integration (e.g., between SI and SII). Finally, global integration involves functional connectivity across large regions of the cortex.

Structure determines function. What neural architectures enable the cortex to perform signal amplification and global integration? While local circuitries in many brain regions perform signal amplification, the cortex also possesses a unique long-distance selective attention pathway arising in the fronto-parietal cortices that is able to amplify neural signals in other cortical regions so that they can be felt (Boly et al., 2011; Lobanov et al., 2013). Global integration is dependent on the propagation of neural activity across the cortex via extensive reciprocal interconnections (axon tracts). These pathways propagate both feedforward and feedback activities (involving both excitatory and inhibitory signals) (Douglas, 1995; Ganguli et al., 2008; Murphy and Miller, 2009). Thus, a defining structural feature underlying the feeling of pain is the strong and direct reciprocal interconnectivity between disparate cortical regions performing pain-related neural computations.

The strength of these interconnections is clearly depicted by the extent of axon innervation and synaptic contributions in any one cortical region arising from other cortical regions. We know from detailed neuroanatomical analyses in the visual system that the primary visual cortex (V1) receives 10 times more input from V2 then from the thalamus via the retina. Moreover, input from all other visual areas is twice that from V2 onto upper layer V1 pyramidal cells (Muckli and Petro, 2013). Thus, interconnections between cortical regions far outweigh those received from sensory stimuli. These observations highlight the importance of feedforward and feedback circuitry in cortical function. In particular, perturbation of these reciprocal connections disrupts visual awareness (Silverstein, 2015).

For pain to have any survival value, it must be mapped to specific body locations. The SI and SII sensory cortices possess topographical maps of the body that process information associated with the somatosensory system. It has been proposed that slight offsets of these maps for different sensations (at least in human SI) have to allow integration of different qualities (e.g., touch and nociception; Mancini et al., 2012; Haggard et al., 2013). This idea has gained considerable support based on recent high-resolution mapping in primates (Vierck et al., 2013). It has been shown that different submodalites of pain, such as sharp-pricking pain and dull-burning pain, are mapped in different subregions of SI. Moreover, local lateral interactions between these subregions significantly alter their relative levels of neural activity (Vierck et al., 2013).

Somatotopic maps of noxious stimuli also exist in the anterior and posterior insular cortex (Brooks et al., 2005; Baumgartner et al., 2010). Separate somatotopic maps are present in noxious stimuli for pinprick and heat within the human anterior insular cortex (Baumgartner et al., 2010). This segregation of sensory inputs raises the possibility that integration occurs between these two sub-modalities and also allows these sub- 
modalities to be integrated with emotional information that reaches the anterior insular cortex (Damasio et al., 2000; Baumgartner et al., 2010; Gu et al., 2010, 2013; Frot et al., 2014).

Amplification and global integration are also dependent on the local microcircuitry in each cortical region (Gilbert, 1983). The local cytoarchitecture of the cortex (the presence of discrete lamina and columnar organisation) is capable of simultaneously maintaining both the differentiation and spatiotemporal relationships of neural signals. For example, separate features or qualities of sensory stimuli can be partitioned to different lamina while the columnar organization enables these signals to be integrated. Both short- and long-range connections between columns provide additional levels of integration. The six-layered neocortex is well suited for this neural processing. Signals from the thalamus terminate in layer 4 and are then passed vertically to layer 2 within a minicolumn. Activity is then projected to layer 5 within the same minicolumn. Strong inhibitory circuits involving interneurons refine the flow of information through this canonical microcircuit (Wolf et al., 2014). The layer 2 neurons project to other cortical regions (local and long-distance) while layer 5 neurons preferentially project to subcortical regions.

The importance of both local and long-distance recurrent feedback in cortical decision making and visuomotor behaviours has been confirmed by computational modeling studies (Sussillo, 2014). Artificial neural networks incorporating recurrent feedback are able to replicate complex neurophysiological data obtained from the monkey prefrontal cortex during the performance of sensorimotor tasks (Mante et al., 2013). Such theoretical and computational approaches are leading to a better understanding of the cortical neurocytoarchitecture necessary to perform conscious neural processing (Martinet et al., 2011; Cox and Dean, 2014; Huang et al., 2015).

Taken together, conscious neural processing involves signal amplification and global integration and arises in the human cortex because of its unique neural architecture. It is proposed here that only vertebrate nervous systems possessing all of the following neuroanatomical features are capable of feeling pain:

1. There must be parcellation of neural tissue into regions with architectures capable of performing pain-related neural computations (e.g., attention, discrimination, localisation, duration, intensity, unpleasantness, valence and motivational value).

2. There also needs to be laminated and columnar organization of canonical neural circuits within neural regions performing pain-related neural computations to allow both differentiation between inputs and preservation of their spatiotemporal relationships. The lamina must possess strong local inhibitory interneuron circuits to filter information. The columns must be capable of integrating various inputs and the laminae also need to convey filtered inputs and integrated outputs to either higher or lower hierarchical regions.

3. Topographical coding of different qualities of somatosensory information in neural regions performing pain-related neural computations should be present. Circuitry must exist that integrates different somatosensory modalities (e.g., light touch versus pain) and sub-modalities (e.g., sharp versus dull pain).

4. Strong reciprocal (i.e., feedforward and feedback) excitatory and inhibitory interconnections between neural regions performing pain-related neural computations as well as other contextually relevant neural processing must also be present (e.g., vision, motor, and working memory). 


\section{Fish Lack the Neural Architecture for Feeling Pain}

Given the proposition that the above organizational principles are necessary for conscious neural processes of pain, and that fish lack many of these prerequisite neuroanatomical features, it is reasonable to conclude that fish do not feel pain. Most notably, fish lack the parcellation of the nervous system into distinct regions with architectures capable of performing pain-related computations; fish also lack a laminated and columnar organization of neural regions that are strongly interconnected by reciprocal feedforward and feedback circuitry.

The fish pallium typically has a small number of structurally discrete regions (some of which are associated with specific sensory stimuli; Northcutt et al., 2004; Ahrens et al., 2013). However, these regions are non-laminated and they are only diffusely interconnected (Giassi et al, 2012). Although the medial pallium is weakly homologous to the mammalian amygdala, these structures principally possess feedforward circuits that execute nociceptive defensive behaviours (Broglio et al., 2005; Duvarci and Pare, 2014; Janak and Tye, 2015). This conclusion is supported by lesion studies that have shown that neither the medial pallium nor the whole pallium is required for escape behaviours from electric shock stimuli in fish (Portavella et al., 2004). Therefore, given that the pallium is not even involved in nociceptive behaviours, it could not be inferred that it plays a role in pain.

While the fish retina projects diffusely to nine nuclei in the diencephalon, its main target is the midbrain optic tectum (Burrill and Easter, 1994). Thus, the fish visual system is highly parcellated, at least, in the sub-telencephalonic regions. Whole brain imaging during visuomotor reflexes reveals widespread neural activity in the diencephalon, midbrain and hindbrain in zebrafish, but these regions appear to act mostly as feedforward pathways (Sarvestani et al., 2013; Kubo et al., 2014; Portugues et al., 2014). When recurrent feedback is present (e.g., in the brainstem circuitry responsible for eye movement), it is weak and usually arises only from the next nucleus within a linear hierarchical circuit (Joshua and Lisberger, 2014). In conclusion, fish lack the strong reciprocal and networked circuitry required for conscious neural processing. Interestingly, the midbrain optic tectum possesses topographic maps, is probably the most highly complex laminated structure in the fish brain, and is capable of integrating a variety of sensorimotor inputs (Robles et al., 2013). However, its ablation does not affect escape responses to either touch or electric shock (Yager et al., 1977). Consequently, the tectum is not involved in nociception and it cannot be concluded that it mediates pain.

A rebuttal to the argument that fish lack the necessary neuroanatomy for feeling pain is that fish have evolved other brain structures to perform pain-related neural processing. That is, while humans have evolved the cortex to feel pain, fish have instead evolved other brain regions to execute the function of pain. Given that there is no evidence for the emergence of novel pain regions in the fish nervous system, it must be assumed that there is a major restructure of existing neural regions in fish to accommodate their additional roles in pain. However, as noted earlier, most of the fish nervous system circuitry is constructed using feedforward pathways that allow rapid execution of unfelt motor programs subserving survival behaviours (Amo et al., 2014; Joshua and Lisberger, 2014; Bianco and Engert, 2015).

An alternative hypothesis as to why fish do not need the architecture of a human cortex to feel pain is because fish do not feel "human pain," but instead they feel "fish pain." Consequently, a cortex-like architecture is not considered necessary for fish to feel pain. 
Interestingly, many people, because of anthropomorphic tendencies, will instinctively endow fish with the ability to feel pain simply because they attempt to escape from noxious stimuli. To indicate that fish do not then feel like humans seems rather contradictory to this anthropomorphism (Key, 2015a). The proposition that fish feel "fish pain" (or pain by any other name, such as "raw experience" or "primitive feelings") is not an argument for fish feeling with another part of their brain. If "fish pain" existed, it would need to be consciously processed using at least the minimal neural architecture described above. Thus, in the absence of this architecture, fish cannot feel any sort of pain. Fish clearly respond to noxious stimuli, and they do so by using feedforward circuitry to execute motor programs. While these behaviours are subject to operant learning using noxious stimuli, they are executed in the absence of feeling pain.

\section{Conclusion}

In the Introduction, I indicated that there is a lack of evidence for fish feeling pain. This has partly been the result of inappropriate use of innate defensive behaviours as a proxy measure of fish feeling pain. This problem is not limited to fish studies. It is recognized that a vast majority of rodent pain studies inappropriately assess reflex behaviours such as tail flick and paw shaking (Barrett, 2015). Consequently, it has been suggested, behaviours that are more indicative of the feeling of pain need to be examined. One suggestion is that the behavioural assay should involve the analysis of loss of a normal behaviour (e.g., feeding or locomotion) rather than the performance of a reflex behaviour (e.g., escape response) (Barrot, 2012; Barrett, 2015). This idea stems from the observation that in humans pain normally tends to be restrictive rather than inducing a specific activity. For instance, human pain usually restricts spontaneous locomotion and perturbs sleep. This has led to a call for animal studies of pain to assess pain-suppressed rather than pain-elicited behaviours. Particular attention should be focused on behaviours relevant for the species under examination.

Given the above concerns about behavioural assays, it is interesting to assess reports of pain-suppressed behaviours in fish in response to surgical interventions known to cause pain in humans. One example of surgery that has been commonly employed in both humans and fish is craniotomy (removal of a portion of skull bone in order to access the brain). In humans, craniotomy typically results in post-surgery pain (verbal reports) (de Gray and Matta, 2005; Roberts, 2005) that diminishes social and physical functioning and leads to an overall reduction in quality of life (Betchen et al., 2003; Rocha-Filho et al., 2008). The gross sensorimotor and locomotor functional deficits observed in rodents following this same surgery (Cole et al., 2011; Lagraoui et al., 2012; Sashindranath et al., 2015) are consistent with the post-craniotomy suppressed behaviours reported by humans. These results lend support to the idea that rodents, like humans, also experience post-craniotomy pain.

What about fish? Do they have suppressed species-specific behaviours after craniotomy? Craniotomy has widely been used in studies involving lesions of the fish brain. In some experiments, the surgery is rather crude and simply involves pushing a hypodermic needle through the cranium and into the forebrain (Kroehne et al., 2011; Kishimoto et al., 2012; Kyritis et al., 2012). Interestingly, after such a stab wound injury, fish continue to exhibit qualitatively normal behaviours; there is no observable suppression of their feeding, swimming and mating behaviours (Schmidt et al., 2014), suggesting that they are not experiencing post-craniotomy pain. Craniotomy also has no effect on specific behaviours of different fish species. For instance, blind cavefish exhibit 
distinct exploratory behaviours when placed into new environments. These behaviours involve time course changes in swim speed and location preference that lead to habituation to novelty. None of these quantitative behaviours were affected by craniotomy, which in this case was performed by drilling a hole in the cranium (Riedel, 1998). Male paradise fish exhibit specific sociosexual courtship behaviours and foamnest building and maintenance. Craniotomy in these fish did not affect feeding, swimming, spawning, courtship behaviours, or building and tending to nests (Davis et al., 1976; Kassel et al., 1976; Schwagmeyer et al., 1977; Davis et al., 1978). Again, the lack of suppression of these behaviours is consistent with these fish not feeling pain after craniotomy.

It is well known that fish can learn to perform motor behaviours using regions of the forebrain (Demski, 2013) that are weakly homologous to the mammalian telencephalon. Direct electrical stimulation of these regions can elicit defensive escape behaviours. However, these observations do not warrant the conclusion that fish have the ability to feel pain or to suffer fear or anxiety (Key, 2015a). Unfortunately, these erroneous inferences are strengthened by beliefs that the motivation to perform certain behaviours is predominantly driven by rewards (either positive or negative). The concept of negative and positive rewards is embedded both in our culture and in the literature, and it arises from our first-hand appreciation of the importance of such rewards (typically thought of as feelings, such as pain and pleasure) in both human basic survival drives as well as complex behaviours. However, there is no sound biological reason to extend these feelings to vertebrates that lack the underlying neuroanatomy and physiology responsible for such feelings in humans.

In the literature it is often suggested that fish feel pain because they can learn to avoid an electric shock by swimming from one region of a fish tank to another when a conditioned stimulus (light) is turned on (Salas et al., 2006; Demski, 2013). It is assumed that fish learn to perform this task because they are motivated by a desire not to experience the electric shock. Emotive concepts such as "fearful," "distressed," "uncomfortable," "overwhelming" and "visceral discomfort" have been invoked to describe the sensations experienced by fish (e.g., see Demski, 2013). That fish have these feelings has been inferred from the observation that specific lesions to pallial subregions can disturb escape responses to conditioned light stimuli. It is believed that in the absence of these pallial regions, a fish no longer feels pain and hence has no motivation to escape when the light is turned on. However, closer analysis of these experiments revealed that when lesioned fish failed to respond to the pre-warning light stimulus and were subsequently electrically shocked, they very quickly exhibited an escape response that was no different from that of controls (Portavella et al., 2004). Thus, the pallium clearly has a role in learning to respond to the light stimulus, but not in responding to the electric shock. These studies support the conclusion that fish do not consciously feel the electric shock, and that fish instead exhibit innate escape responses involving non-conscious subpallial pathways.

While it may be appropriate to retain the nomenclature of positive and negative rewards for fish, it should be done in the context of understanding that these animals do not perform behaviours to be rewarded with pleasurable feelings or alternatively to escape painful feelings, but they do so because the circuitry has evolved to ensure survival. The fact that a spinal-cord-lesioned rodent can learn to uniquely position its lower limb in order to prevent exposure to an electric shock is a classic example of such survival circuitry (Grau, 2014). This behaviour is executed clearly without feeling, and the shock 
is merely a noxious stimulus that activates neural circuitry that is both beneficial for survival and indicate of the capacity to learn.

It has been argued here that it is possible to logically and confidently propose the strong inference, based on principles of evolutionary biology and neuroscience, that fish do not feel noxious stimuli. I acknowledge that we do not have the tools at present to definitively "prove" with a single experimental approach that fish do not feel pain. There are questions in science that are difficult, and simple demonstrations or proof are not available. For example, we can neither re-run the evolution of multicellular organisms, nor reconstruct the universe from the big bang, in order to test definitively the standard scientific models of the origins of animals and the universe. Given that explaining consciousness is generally considered the hardest problem of neuroscience, it is not surprising that simple demonstrations or proof are not available. What then do noxious stimuli feel like to a fish? The evidence best supports the idea that they don't feel like anything to a fish.

Disclosure statement: The author states that he has not been paid for this work and has no conflict of interest.

Call for Commentary: Animal Sentience publishes Open Peer Commentary on all accepted target articles. Target articles are peer-reviewed. Commentaries are editorially reviewed. There are submitted commentaries as well as invited commentaries. Commentaries appear as soon as they have been revised and accepted. Target article authors may respond to their commentaries individually or in a joint response to multiple commentaries.

Instructions: $\mathrm{http}: / /$ animalstudiesrepository.org/animsent/guidelines.html

\section{References}

Afif, A., Hoffman, D., Minotti, L., Benabid, A.L. and Kahane, P. (2008). Middle short gyrus of the insula implicated in pain processing. Pain. 138:546-555.

Afif, A., Minotti, L., Kahane, P. and Hoffman, D. (2010). Anatomofunctional organization of the insular cortex: a study using intracerebral electrical stimulation in epileptic patients. Epilep. 51:2305-2315.

Ahrens, M.B., Huang, K.H., Narayan, S., Mensh, B.D. and Engert, F. (2013). Two-photon calcium imaging during fictive navigation in virtual environments. Front. Neural Circ. 7:a104.

Alstott, J., Breakspear, M., Hagmann, P., Cammoun, L. and Sporns, O. (2009). Modeling the impact of lesions in the human brain. PLoS Comput. Biol. 5:e1000408.

Amo, R., Fredes, F., Kinoshita, M., Aoki, R., Aizawa, H., Agetsuma, M., Aoki, T., Shiraki, T., Kakinuma, H., Matsuda, M., Yamazaki, M., Takahoko, M., Tsuboi, T., Higashijima, S., Miyasaka, N., Koide, T., Yabuki, Y., Yoshihara, Y., Fukai, T. and Okamoto, H. (2014). The habenulo-raphe serotonergic circuit encodes an aversive expectation value essential for adaptive active avoidance of danger. Neuron 84:1034-1048. 
Arlinghaus, R., Cooke, S.J., Schwab, A. and Cowx, I.G. (2007). Fish Welfare: a challenge to the feelings-based approach, with implications for recreational fishing. Fish Fisher. 8:57-71.

Aylward, G.P., lazzara, A. and Meyer, J. (1978). Behavioural and neurological characteristics of a hydranencephalic infant. Develop. Med. Child Neurol. 20:211-217.

Baier, B., zu Eulenburg, P., Geber, C., Rohde, F., Rolke, R., Maihofner, C., Birklein, F. and Dieterich, M. (2014). Insula and sensory insular cortex and somatosensory control in patients with insular stroke. Eur. J. Pain 18:1385-1393.

Barnet, A., Bazelon, M. and Zappella, M. (1966). Visual and auditory function in an hydranencephalic infant. Brain Res. 2:351-360.

Barrett, J.E. (2015). The pain of pain: challenges of animal behaviour models. Eur. J. Pharmacol. 753:183-190.

Barrot, M. (2012). Tests and models of nociception and pain in rodents. Neurosci. 211: 3950.

Barttfeld, P., Uhrig, L., Sitt, J.D., Sigman, M., Jarraya, B. and Dehaene, S. (2015). Signature of consciousness in the dynamics of resting-state brain activity. PNAS 112:887-892.

Bassetti, C., Bogousslavsky, J. and Regli, F. (1993). Sensory syndromes in parietal stroke. Neurol. 1942-1949.

Baumbauer, K.M., Young, E.E. and Joynes, R.L. (2009). Pain and learning in a spinal system: contradictory outcomes from common origins. Brain Res. Rev. 61:124-143.

Baumgartner, U., Iannetti, G.D., Zambreanu, L., Stoeter, P., Treede, R-D. and Tracey, I. (2010). Multiple somatotopic representations of heat and mechanical pain in the operculo-insular cortex: a high-resolution fMRI study. J. Neurophysiol. 104:28632872.

Benison, A.M., Chumachenko, S., Harrison, J.A., Maier, S.F., Falci, S.P., Watkins, L.R. and Barth, D.S. (2011). Caudal granular insular cortex is sufficient and necessary for the long-term maintenance of allodynic behaviour in the rat attributable to mononeuropathy. J. Neurosci. 31:6317-6328.

Berthier, M., Starkstein, S. and Leiguarda, R. (1987). Behavioural effects of damage to the right insula and surrounding regions. Cortex 23:673-678.

Berthier, M., Starkstein, S. and Leiguarda, R. (1988). Aymbolia for pain: a sensory-limbic disconnection syndrome. Ann. Neurol. 24:41-49.

Betchen, S.A., Walsh, J. and Post, K.D. (2003). Self-assessed quality of life after acoustic neuroma. J. Neurosurg. 99:818-823. 
Bianco, I.H. and Engert, F. (2015). Visuomotor transformations underlying hunting behaviour in zebrafish. Curr. Biol. 25:1-16.

Biemond, A. (1956). The conduction of pain above the level of the thalamus opticus. Arch. Neurol. Psych. 75:231-244.

Biswal, B., Yeskin, F.Z., Haughton, V.M. and Hyde, J.S. (1995). Functional connectivity in the motor cortex of resting human brain using echo-planar MRI. Mag. Reson. Med. 34:537541.

Boly, M., Garrido, M.I., Gosseries, O., Bruno, M-A., Boveroux, P., Schnakers, C., Massimini, M., Litvak, V., Laureys, S. and Friston, K. (2011). Preserved feedforward but impaired top-down processes in the vegetative state. Science 332:858-862.

Bosman, C.A., Lansink, C.S. and Pennartz, C.M.A. (2014). Functions of gamma-band synchronization in cognition: from single circuits to functional diversity across cortical and subcortical systems. Eur. J. Neurosci. 39:1982-1999.

Broglio, C., Gomez, A, Duran, E., Ocana, F.M., Jimenez-Moya, F., Rodriguez, F. and Salas, C. (2005). Hallmarks of a common vertebrate plan: specialised pallial areas for spatial, temporal; and emotional memory in actinopterygian fish. Brian Res. Bull. 66:277-281.

Bromm, B. and Lorenz, J. (1998). Neurophysiological evaluation of pain. Electroencephalogr. Clin. Neurophysiol. 107:227-253.

Brooks, J.C.W., Zambreanu, L., Godinez, A., Craig, A.D. and Tracey, I. (2005). Somatotopic organization of the human insula to painful heat studies with high resolution functional imaging. NeuroImage 27:201-209.

Brown, K.F., Long, S.J., Ramsay, M., Hudson, M.J., Green, J., Vincent, C.A., Kroll, J.S., Fraser, G. and Sevdalis, N. (2012). U.K. parents' decision-making about measles-mumpsrubella (MMR) vaccine 10 years after the MMR-autism controversy: a qualitative analysis. Vaccine 30:1855-1864.

Burrill, J.D. and Easter, S.S. (1994). Development of the retinofugal projections in the embryonic and larval zebrafish (Brachydanio rerio). J. Comp. Neurol. 346:583-600.

Buzsaki, G. and Schomburg, E.W. (2015). What does gamma coherence tell us about interregional communication. Nature Neurosci. 4:484-489.

Capistrano, R.C.G. and Charles, A.T. (2012). Indigenous rights and coastal fisheries: a framework of livelihoods, rights and equity. Ocean Coast Manag. 69:200-229.

Casali, A.G., Gosseries, O., Rosanova, M., Boly, M., Sarasso, S., Casali, K.R., Casarotto, S., Bruno, M-A., Laureys, S., Tononi, G. and Massimini, M. (2014). A theoretically based index of consciousness independent of sensory processing and behaviour. Sci. Transl. Med. 5:198ra105.

Cecchetto, G., Milanese, L., Giordano, R., Viero, A., Suma, V. and Manara, R. (2013). 
Looking at the missing brain: hydraencephaly case series and literature review. Pedr. Neurol. 48:152-158.

Cerrato, P., Imperiale, D., Bergui, M., Giraudo, M., Baima, CV., Grasso, M., Lentini, A. and Bergamasco, B. (2003). Emotional facial paresis in a patient with lateral medullary infarct. Neurol. 60:723-724.

Cerrato, P., Lentini, A., Baima, C., Grasso, M., Azzaro, C., Bosco, G., Bergamasco, B. and Benna, P. (2005). Pseudo-ulnar sensory loss in a patient from a small cortical infarct of the postcentral knob. Neurol. 64:1981-1982.

Changeux, J-P. (2012). Conscious processing: implications for general anesthesia. Curr. Opin. Anaesthesiol. 25:398-404.

Cobb, E.J. and Portillo-Salido, E. (2013). "Bedside to bench" behavioral outcomes in animal models of pain: beyond the evaluation of reflexes. Curr. Neuropharmacol. 11:560-591.

Coffeen, U., Manuel Ortega-Legaspi, J., Lopez-Munoz, F.J., Simon-Arceo, K., Jaimes, O. and Pellicer, F. (2011). Insular cortex lesion diminishes neuropathic anmd inflammatory pain-like behaviours. Eur. J. Pain 15:132-138.

Cole, J.T., Yarnell, A., Kean, W.S., Gold, E., Lewis, B., Ren, M., McMullen, D.C., Jacobwitz, D.M., Pollard, H.B., O'Neill, J.T., Grunberg, N.E., Dalgard, C.L., Frank, J.A. and Watson, W.D. (2011). Craniotomy: true sham for traumatic brain injury, or a sham of a sham? J. Neurotrauma 28:359-369.

Constant, I. and Sabourdin, N. (2015). Monitoring depth of anaesthesia: from consciousness to nociception. A window on subcortical brain activity. Pediatr. Anaesthesiol. 25:73-82.

Cox, D.D. and Dean, T. (2014). Neural networks and neuroscience-inspired computer vision. Curr. Biol. 24:R921-R929.

Crown, E.D., Ferguson, A.R., Joynes, R.L. and Grau, J.W. (2002). Instrumental learning within the spinal cord: IV. Induction and retention of the behavioural deficit observed after noncontingent shock. Behav. Neurosci. 116:1032-1051.

Dalby, D.A., Meyer, D.R. and Meyer, P.M. (1970). Effects of occipital neocortical lesions upon visual discriminations in the cat. Physiol. Behav. 5:727-734.

Damasio, A. and Carvalho, G.B. (2013). The nature of feelings: evolutionary and neurobiological origins. Nature Rev. Neurosci. 14:143-152.

Damasio, A., Damasio, H. and Tranel, D. (2012). Persistence of feelings and sentience after bilateral damage of the insula. Cer. Cortex 23:833-846.

Damasio, A.R., Grabowski, T.J., Bechara, A., Damasio, H., Ponto, L.L.B., Parvizi, J. and Hichwa, R.D. (2000). Subcortical and cortical activity during the feeling of selfgenerated emotions. Nature Neurosci. 3:1049-1056. 
Daou, I., Tuttle, A.H., Longo, G., Wieskopf, J.S., Bonin, R.P., Ase, A.R., Wood, J.N., De Koninck, Y., Ribeiro-da-Silva, A., Mogil, J.S. and Seguela, P. (2013). Remote optogenetic activation and sensitization of pain pathways in freely moving mice. J. Neurosci. 33:18631-18640.

Davidson, E.H. and Erwin, D.H. (2006). Gene regulatory networks and the evolution of animal body plans. Science 311:796-800.

Davis, R.E., Kassel, J. and Schwagmeyer, P. (1976). Telencephalic lesions and behavior in the teleost, Macropodus opercularis: reproductive, startle reaction, and operant behavior in the male. Behav. Biol. 18:165-177.

Davis, R.E., Reynolds, R.C. and Ricks, A. (1978). Suppression behaviour increased by telencephalic lesions in the Teleost, Macropodus opercularis. Behav. Biol. 24:32-48.

de Gray, L.C. and Matta, B.F. (2005). Acute and chronic pain following craniotomy: a review. Anaesthesia 60:693-704.

Dehaene, S., Charles, L., King, J-R. and Marti, S. (2014). Toward a computational theory of conscious processing. Curr. Opin. Neurobiol. 25:76-84.

Demski, L.S. (2013). The pallium and mind/behaviour relationships in teleost fishes. Brain Behav. Evol. 82:31-44.

Devor, M., Rappaport, I., Rappaport, Z.H. (2014). Does the golem feel pain? Moral instincts and ethical dilemmas concerning suffering and the brain. Pain Pract. doi: 10.1111/papr.12207

Diggles, B.K., Cooke, S.J., Rose, J.D. and Sawynok, W. (2011). Ecology and welfare of aquatic animals in wild capture fisheries. Rev. Fish Biol. Fisheries 21:739-765.

Douglas, R.J., Koch, C., Mahowald, M., Martin, K.A.C. and Suarez, H.H. (1995). Recurrent excitation in neocortical circuits. Science 269:981-985.

Duffau, H., Taillandier, L., Gatignol, P. and Capelle, L. (2006). The insular lobe and brain plasticity: lessons from tumour surgery. Clin. Neurol. Neurosurg. 108:543-548.

Duvarci, S. and Pare, D. (2014). Amygdala microcircuits controlling learned fear. Neuron 82:966-980.

Engel, A.K. and Singer, W. (2001). Temporal binding and the neural correlates of sensory awareness. Trends Cogn. Sci. 5:16-25.

Engel, A.K., Koenig, P., Kreiter, A.K. and Singer, W. (1991). Interhemispheric synchronization of oscillatory neuronal responses in cat visual cortex. Science 252:1177-1179. 
Feinstein, J.S., Khalsa, S.S., Salomons, T.V., Prkachin, K.M., Frey-Law, L.A., Lee, J.E., Tranel, D. and Rudrauf, D. (2015). Preserved emotional awareness of pain in apatient with extensive bilateral damage to the insula, anterior cingulate, and amygdala. Brain Struct. Funct. doi: 10.1007/s00429-014-0986-3.

Ferrier, R.J. and Cooper, R.M. (1976). Striate cortex ablation and spatial vision. Brain Res. 106:71-85.

Flaherty, D.K. (2011). The vaccine-autism connection: a public health crisis caused by unethical medical practices and fraudulent science. Ann. Pharmacother. 45:13021304.

Fries, P., Nikolic, D. and Singer, W. (2007). The gamma cycle. Trends Neurosci. 30:309316.

Fries, P.O. (2009). Neuronal gamma-band synchronization as a fundamental process in cortical computation. Annu. Rev. Neurosci. 32:209-224.

Frigon, A. (2012). Central pattern generators of the mammalian spinal cord. Neurosci. 18:56-69.

Friston, K.J., Frith, C.D., Liddle, P.F. and Frackowiak, R.S.J. (1993). Functional connectivity: the principal-component analysis of large (PEWT) data sets. J. Cerebr. Blood Flow Metab. 13:5-14.

Frot, M., Faillenot, I. and Mauguiere, F. (2014). Processing of nociceptive input from posterior to anterior insula in humans. Hum. Brain Mapp. 35:5486-5499.

Ganguli, S., Bisley, J.W., Roitman, J.D., Shadlen, M.N., Goldberg, M.E. and Miller, K.D. (2008). One-dimensional dynamics of attention and decision making in LIP. Neuron 58:15-25.

Garcia-Larrea, L. (2012a). Insights gained into pain processing from patients with focal brain lesions. Neurosci. Lett. 520:188-191.

Garcia-Larrea, L. (2012b). The posterior insular-opercular region and the search of a primary cortex for pain. Clin. Neurophysiolog. 42:299-313.

Garcia-Larrea, L. and Peyron, P. (2013). Pain matrices and neuropathic pain matrices: a review. Pain 154:529-543.

Garcia-Larrea, L., Charles, N., Sindou, M. and Mauguiere, F. (1993). Flexion reflexes following anterolateral cordotomy in man: dissociation between pain sensation and nociceptive reflex RIII. Pain 139:149.

Giassi, A.C.C., Ellis, W. and Maler, L. (2012). Organization of the gymnotiform fish pallium in relation to learning and memory: III. Intrinsic connections. J. Comp. Neurol. 520:3369-3394.

Gilbert, C.D. (1983). Microcircuitry of the visual cortex. Ann. Rev. Neurosci. 6:217-247. 
Glassman, R.B. (1987). An hypothesis about redundancy and reliability in the brains of higher species: analogies with genes, internal organs, and engineering systems. Neurosci. Biobehav. Rev. 11:275-285.

Godwin, D., Barry, R.L. and Marois, R. (2015). Breakdown of the brain's functional network modularity with awareness. PNAS 112:3799-3804

Goffart, L., Hafed, Z.M. and Krauzlis, R. (2012). Visual fixation as equilibrium: evidence from superior colliculus inactivation. J. Neurosci. 32:10627-10636.

Goulding, M. (2009). Circuits controlling vertebrate locomotion: moving in a new direction. Nature Rev. Neurosci. 10:507-518.

Grau, J.W. (2014). Learning from the spinal cord: how the study if spinal cord plasticity informs our view of learning. Neurobiol. Learn. Mem. 108:155-171.

Gray, C.M. and Singer, W. (1989). Stimulus-specific neuronal oscillations in orientation columns of cat visual cortex. Proc. Natl. Acad. Sci. USA 86:1698-1702.

Gray, C.M., Koenig, P., Engel, A.K. and Singer, W. (1989). Oscillatory responses in cat visual cortex exhibit inter-columnar synchronization which reflects global stimulus properties. Nature 338:334-337.

Greenspan, J.D., Lee, R.R. and Lenz, F.A. (1999). Pain sensation alterations as a function of lesion location in the parasylvian cortex. Pain 81:273-282.

Gregoriou, G.G., Gotts, S.J., Zhou, H. and Desimone, R. (2009). High-frequency, long-range coupling between prefrontal and visual cortex during attention. Science 324:12071210.

Gross, J., Schnitzler, A., Timmermann, L. and Ploner, M. (2007). Gamma oscillations in human primary somatosensory cortex reflect pain perception. PLOS Biol 5:e133.

Gu, L., Uhelski, M.L., Anand, S., Romero-Ortega, M., Kim, Y-T., Fuchs, P.N. and Mohanty, S.K. (2015). Pain inhibition by optogenetic activation of specific anterior cingulate cortical neurons. PLoS ONE: 10(2):e0117746.

Gu, X., Gao, Z., Wang, X., Liu, X., Knight, R.T., Hof, P.R. and Fan, J. (2010). Anterior insular cortex is necessary for empathetic pain perception. Brain 135:2726-2735.

Gu, X., Liu, X., Van Dam, N.T., Hof, P.R. and Fan, J. (2013). Cognition-emotion integration in the anterior insular cortex. Cereb. Cortex 23:20-27.

Haggard, P., Iannetti, G.D. and Longo, M.R. (2013). Spatial sensory representation in pain perception. Curr. Biol. R164-R176. 
Hauck, M., Lorenz, J. and Engel, A.K. (2007). Attention to painful stimulation enhances gamma-band activity and synchronization in human sensorimotor cortex. J. Neurosci. 27:9270-9277.

Hauck, M., Lorenz, J. and Engel, A.K. (2009). Role of synchronized oscillatory brain activity for human pain perception. Rev. Neurosci. 19:441-450.

Hedges, S.B. (2002). The origin and evolution of model organisms. Nature. 3:838-849.

Hill, K., Gogan, D.G. and Dodge, P.R. (1961). Ocular signs associated with hydranencephaly. Am. J. Ophthalmol. 51:267-275.

Hipp, J.F., Engel, A.K. and Siegel, M. (2011). Oscillatory synchronization in large-scale cortical networks predicts perception. Neuron. 69:387-396.

Horowitz, A.C. and Bekoff, M. (2007). Naturalizing anthropomorphism: behavioural prompts to our humanizing of animals. J. Interact. People Anim. 20:23-35.

Horwitz, B., Hwang, C. and Alstott, J. (2013). Interpretting the effects of altered brain anatomical connectivity on fMRI functional connectivity: a role for computational neural modelling. Front. Hum. Neurosci. 7:a649.

Huang, D.W., Gentili, R.J. and Reggia, J.A. (2015). Self-organizing maps based on limit cycle attractors. Neural Net. 63:208-222.

Iannetti, G.D. and Mouraux, A. (2010). From the neuromatrix to the pain matrix (and back). Exp. Brain Res. 2015:1-12.

Iannetti, G.D., Hughes, N.P., Lee, M.C. and Mouraux, A. (2008). Determinants of laserevoked EEG responses: pain perception or stimulus saliency? J. Neurophysiol. 100:815-828.

Iannetti, G.D., Zambreanu, L., Cruccu, G. and Tracey, I. (2005). Operculoinsular cortex encodes pain intensity at the earliest stages of cortical processing as indicated by amplitude of laser-evoked potentials in humans. Neurosci. 131:199-208.

Janak, P.H. and Tye, K.M. (2015). From circuits to behaviour in the amygdala. Nature Rev. Neurosci. 517:284-292.

Jindrich, D.L., Joseph, M.S., Otoshi, C.K., Wei, R.Y., Zhong, H., Roy, R.R., Tillakaratne, N.J.K. and Edgerton, V.R. (2009). Spinal learning in the adult mouse using the Horridge paradigm. J. Neurosci. Meth. 182:250-254.

Johansen, J.P., Field, H.L. and Manning, B.H. (2001). The affective component of pain in rodents: direct evidence from a contribution of the anterior cingulate cortex. PNAS. 98:8077-8082.

Joshua, M. and Lisberger, S.G. (2014). A tale of two species: neural integration in zebrafish and monkeys. Neurosci. doi: 10.1016/j.neuroscience.2014.04.048 
Kalberlah, C., Villringer, A. and Pleger, B. (2013). Dynamic causal modelling suggests serial processing of tactile vibratory stimuli in the human somatosensory cortex - an fMRI study. NeuroImage. 74:164-171.

Kanai, R. and Tsuchiya, N. (2012). Qualia. Curr. Biol. 22:R392-R396.

Kassel, J., Davis, R.E. and Schwagmeyer, P. (1976). Telencephalic lesions and behaviour in the Teleost, Macropodus opercularis: Further analysis of reproductive and operant behaviour in the male. Behav. Biol. 18:179-188.

Kato, R., Takaura, K., Ikeda, T., Yoshida, M. and Isa, T. (2011). Contribution of the retintectal pathway to visually guided saccades afterlesion of the primary visual cortex in monkeys. Eur. J. Neurosci. 33:1952-1960.

Keller, A. (2014). The evolutionary function of conscious information processing is revealed by its task-dependency in the olfactory system. Front. Psychol. doi: 10.3389/fpsyg.2014.00062

Key, B. (2015a). Fish do not feel pain and its implications for understanding phenomenal consciousness. Biol. Phil. 30:149-155. doi: 10.1007/s10539-014-9469-4

Key, B. (2015b). Why fish (likely) don't feel pain. Scientia Salon, February $5^{\text {th }}$. Available at https://scientiasalon.wordpress.com

Khoshnejad, M., Piche, M., Saleh, S., Duncan, G. and Rainville, R. (2014). Serial processing in primary and secondary somatosensory cortex: a DCM analysis of human fMRI data in response to innocuous and noxious electrical stimulation. Neurosci. Lett. 577:8388.

King, J-R., Sitt, J.D., Faugeras, F., Rohaut, B., Karoui, I.E., Cohen, L., Naccache, L. and Dehaene, S. (2013). Information sharing in the brain indexes consciousness in noncommunicative patients. Curr. Biol. 23:1914-1919.

Kishimoto, N., Shimizu, K. and Sawamoto, K. (2012). Neuronal regeneration in a zebrafish model of brain injury. Disease Mod. Mech. 5:200-209.

Kroehne, V., Freudenreich, D., Hans, S., Kaslin, J. and Brand, M. (2011). Regeneration of the adult zebrafish brain from neurogenic radial glia-type progenitors. Develop. 138:4831-4841.

Kubo, F., Hablitzel, B., Dal Maschio, M., Driever, W., Baier, H. and Arrenberg, A.B. (2014). Functional architecture of an optic flow-responsive area that drives horizontal eye movement in zebrafish. Neuron. 81:1344-1359.

Kucyi, A. and Davis, K.D. (2015). The dynamic pain connectome. Trends Neurosci. 38:8695. 
Kyritsis, N., Kizil, C., Zocher, S., Kroehne, V., Kaslin, J., Freudenreich, D., Iltzsche, A. and Brand, M. (2012). Acute inflammation initiates the regenerative response in adult zebrafish brain. Science. 338:1353-1356.

Lagraoui, M., Latoche, J.R., Cartwright, N.G., Sukumar, G., Dalgard, C.L. and Schaefer, B.C. (2012). Controlled cortical impact and craniotomy induce strikingly similar profiles of inflammatory gene expression, but without distinct kinetics. Front. Neurol. 3:155.

Laureys, S. (2005). The neural correlate of (un)awareness: lessons from the vegative state. Trends Cogn. Sci. 9:556-559.

LeDoux, J.E. (2012). Rethinking the emotional brain. Neuron. 73:653-676.

LeDoux, J.E. (2013). The slippery slope of fear. Trends Cogn. Sci. 17:155-156.

LeDoux, J.E. (2014a). Coming to terms with fear. PNAS USA. 111:2871-2878.

LeDoux, J.E. (2014b). Low roads and higher order thoughts and emotions. Cortex. 59:214215.

Lee, H.W., Hong, S.B., Seo, D.W., Tae, W.S. and Hong, S.C. (2000). Mapping of functional organization in human visual cortex: electrical cortical stimulation. Neurol. 54:849854.

Liang, M., Mouraux, A. and Iannetti, G.D. (2011). Parallel processing of nociceptive and non-nociceptive somatosensory information in the human primary and secondary somatosensory cortices: evidence form dynamic causal modelling of functional magnetic resonance imaging data. J. Neurosci. 31:8976-8985.

Lobanov, O.V., Quevedo, A.S., Hadsel, M.S., Kraft, R.A. and Coghill, R.C. (2013). Frontoparietal mechanisms supporting attention to location and intensity of painful stimuli. Pain. 154:1758-1768.

Lockwood, P.L., Iannetti, G.D. and Haggard, P. (2013). Transcranial magnetic stimulation over secondary somatosensory cortex disrupts pain intensity. Cortex. 49:2201-2209.

Lu, X.-C.M. and Slotnick, B.M. (1998). Olfaction in rats with extensive lesions of the olfactory bulbs: implications for odor coding. Neurosci. 84:849-866.

Mancini, F., Haggard, P., Iannetti, G.D., Longo, M.R. and Sereno, M.I. (2012). Fine-grained nociceptive maps in primary somatosensory cortex. J. Neurosci. 32:17155-17162.

Mano, H. and Seymour, B. (2015). Pain: a distributed brain information network? PLOS Biol. 13:e1002037.

Mante, V., Sussillo, D., Shenoy, K.V. and Newsome, W.T. (2013). Context-dependent computation by recurrent dynamics in prefrontal cortex. Nature. 503:78-84. 
Martinet, L-E., Sheynikhovich, D., Benchenane, K. and Arleo, A. (2011). Spatial learning and action planning in a prefrontal cortical network model. PLoS Comput. Biol. 7:e1002045.

Mashour, G.A. (2013). Cognitive binding: a neuroscientific paradigm of general anaesthesia and related states of unconsciousness. Neurosci. Biobehav. Rev. 37:27512759.

Maugiere, F. and Desmedt, J.E. (1988). Thalamic pain syndrome of Dejerine-Roussy. Differentiation of four subtypes assisted by somatosensory evoked potentials data. Arch. Neurol. 45:1312-1320.

Mazzola, L., Isnard, J., Peyron, R., Guenot, M. and Mauguiere, F. (2009). Somatotopic organization of pain responses to direct electrical stimulation of the human insular cortex. Pain. 146:99-104.

Mazzola, L., Isnard, J., Peyron, R. and Mauguiere, F. (2012). Stimulation of the human cortex and the experience of pain: Wilder Penfield's observations revisited. Brain. 135:631-640.

Mazzola, L., Lopez, C.L., Faillenot, I., Chouchou, F., Mauguiere, F. and Isnard, J. (2014). Vestibular responses to direct stimulation of the human insular cortex. Ann. Neurol. 76:609-619.

McAbee, G.N., Chan, A. and Erde, E.L. (2000). Prolonged survival with hydraencephaly: report of two patients and literature review. Pedr. Neurol. 23:80-84.

Melzack, R. (1999). From gate to the neuromatrix. Pain Suppl. 6:S121-S126.

Meyer, M.L., Masten, C.L., Ma, Y., Wang, C., Shi, Z., Eisenberger, N.I. and Han. S. (2012). Empathy for the social suffering of friends and strangers recruits distinct patterns of brain activation. Soc. Cogn. Affect. Neurosci. 8:446-454.

Millan, M.J. (2002). Descending control of pain. Prog. Neurobiol. 66:355-474.

Moayedi, M. (2014). All roads lead to the insula. Pain. 155:1920-1921.

Mouraux, A., Diukova, A., Lee, M.C., Wise, R.G. and Iannetti, G.D. (2011). A multisensory investigation of the functional significance of the "pain matrix". Nueroimage. 54:22372249.

Muckli, L. and Petro, L.S. (2013). Network interactions; non-geniculate input to V1. Cur. Opin. Neurobiol. 23:195-201.

Murphy, B.K. and Miller, K.D. (2009). Balanced amplification: a new mechanism of selective amplification of neural activity patterns. Neuron. 61:635-648.

Nagel, T. (1974). What it is like to be a bat? Philos. Rev. 83:435-450. 
Nguyen, M.N., Matsumoto, J., Hori, E., Maior, R.S., Tomaz, C., Tran, A.H., Ono, T. and Nishijo, H. (2014). Neuronal responses to face-like and facial stimuli in the monkey superior colliculus. Front. Behav. Neurosci. 8:a85.

Nierhaus, T., Forschack, N., Piper, S.K., Holtze, S., Krause, T., Taskin, B., Long, X., Steizer, J., Margulles, D.S., Steinbronk, J. and Villringer, A. (2015). Imperceptible somatosensory stimulation alters sensorimotor background rhythm and connectivity. J. Neurosci. 35:5917-5925.

Nikolic, D., Fries, P. and Singer, W. (2013). Gamma oscillations: precise temporal coordination without a metronome. Trends Cogn. Sci. 17:54-55.

Northcutt, R.G., Plassmann, W., Homles, P.H. and Saidel, W.M. (2004). A pallial visual area in the telencephalon of the bony fish Polypterus. Brain Behav. Evol. 64:1-10.

Orpwood, R. (2013). Qualia could arise from information processing in local cortical networks. Front. Psychol. 4:121.

Ostrowsky, K., Magnin, M., Ryvlin, P., Isnard, J., Guenot, M. and Mauguiere, F. (2002). Representation of pain and somatic sensation in the human insula: a study of responses to direct electrical stimulation. Cerebr. Cort. 12:376-385.

Panksepp, J. (2011). Cross-species affective neuroscience decoding of the primal affective experiences of humans and related animals. PLoS ONE. 6(9):e21236.

Park, H.-J. and Friston, K. (2013). Structural and functional brain networks: from connections to cognition. Science. 342:1238411.

Pasik, P., Pasik, T. and Schilder, P. (1969). Extrageniculostriate vision in the monkey: discrimination of luminous flux-equated figures. Exper. Neurol. 24:421-437.

Pavone, P., Praticò, A.D., Vitali, G., Ruggieri, M., Rizzo, R., Parano, E., Pavone, L., Pero, G. and Falsaperia, R. (2014). Hydraencephaly: cerebral spinal fluid instead of cerebral mantles. Ital. J. Pediatr. 40:79.

Peltz, E., Seifert, F., DeCol, R., Dorfler, A., Schwab, S. and Malhofner, C. (2011). Functional connectivity of the human insular cortex during noxious and innocuous thermal sensation. Neuroimage. 15:1324-1335.

Penfield, W. and Faulk, M.E. (1955). The insula. Further observations on its function. Brain. 78:445-470.

Penfield, W. and Perlot, P. (1963). The brain's record of auditory and visual experience. A final summary and discussion. Brain. 86:595-696.

Ploner, M., Freund, H.-J. and Schnitzler, A. (1999). Pain affect without pain sensation in a patient with a postcentral lesion. Pain. 81:211-214. 
Ploner, M., Schoffelen, J-M., Schnitzler, A. and Gross, J. (2009). Functional integration within the human pain system as revealed by Granger causality. Hum. Brain Map. 30:4025-4032.

Porro, C.A., Martinig, M., Facchin, P., Maieron, M., Jones, A.K.P. and Fadiga, L. (2007). Parietal cortex involvement in the localisation of tactile and noxious mechanical stimuli: a transcranial magnetic stimulation study. Behav. Brain Res. 178:183-189.

Portavella, M., Torres, B. and Salas, C. (2004). Avoidance response in goldfish: emotional and temporal involvement of medial and lateral telencephalic pallium. J. Neurosci. 24:2335-2342.

Portugues, R., Feierstein, C.E., Engert, F. and Orger, M.B. (2014). Whole-brain activity maps reveal stereotypes, distributed networks for visuomotor behaviour. Neuron. 81:13281343.

Pritchett, D.L., Siegle, J.H., Deister, C.A. and Moore, C.I. (2015). For things needing your attention: the role of neocortical gamma in sensory perception. Curr. Opin. Neurobiol. 31:254-263.

Qiu, S., Chen, T., Koga, Y-Y., Xu, H., Song, Q., Wang, J-J., Descalzi, G., Kaang, B-K., Luo, J-H., Zhuo, M. and Zhao, M-G. (2013). An increase in synaptic NMDA receptors in the insular cortex contributes to neuropathic pain. Sci. Sig. 6(275):ra34.

Qiu, S., Zhang, M., Liu, Y., Guo, Y., Zhao, H., Song, Q., Zhao, M., Huganir, R.L., Luo, J., Xu, H. and Zhuo, M. (2014). GluA1 phosphorylation contributes to postsynaptic amplification of neuropathic pain in the insular cortex. J. Neurosci. 34:13505-13515.

Qu, C., King, T., Okun, A., Lai, J., Fields, H.L. and Porreca, F. (2011). Lesion of the rostral anterior cingulate cortex eliminates the aversiveness of spontaneous neuropathic pain following partial or complete axotomy. Pain. 152:1641-1648.

Radoš, M., Klarica, M., Mučić-Pucić, NIkić, I., Raguź, M., Galkowski, V., Mandić, D. and Oreśkovic, D. (2014). Volumetric analysis of cerebrospinal fluid and brain parenchyma in a patient with hydraencephaly and macrocephaly - case report. Croat. Med. J. 55:388-393.

Riedel, G. (1998). Long-term habituation to spatial novelty in blind cave fish (Astyanax hubbsi): role of the telencephalon and its subregions. Learn. Mem. 4:451-461.

Roberts, G.C. (2005). Post-craniotomy analgesia: current practices in British neurosurgical centres - a survey of post-craniotomy analgesic practices. Eur. J. Anaesthesiol. 22:328-332.

Robles, E., Filosa, A. and Baier, H. (2013). Precise lamination of retinal axons generates multiple parallel input pathways in the tectum. J. Neurosci. 33:5027-5039.

Rocha-Filha, P.A.S., Gherpelli, J.L.D., de Siqueira, J.T.T. and Rabello, G.D. (2008). Postcraniotomy headache: characteristics, behaviour and effect on quality of life in 
patients operated for treatment of supratentorial intracranial aneurysms, Cephal. 28:41-48.

Roeser, R.J. and Daly, D.D. (1974). Auditory cortex disconnection associated with thalamic tumor. Neurol. 24:555-559.

Rolls, E.T. (2007). A computational neuroscience approach to consciousness. Neural Net. 20:962-982.

Rolls, E.T. (2014a). Emotion and decision-making explained: a précis. Cortex. 59:185-193.

Rolls, E.T. (2014b). Emotion and decision-making explained: response to commentators. Cortex. 59:203-210.

Rosa, M.J. and Seymour, B. (2014). Decoding the matrix: benefits and limitations of applying machine learning algorithms to pain neuroimaging. Pain. 155:864-867.

Rose, J.D., Arlinghaus, R., Cooke, S.J., Diggles, B.K., Sawynok, W., Stevens, E.D. and Wynne, C.D.L. (2014). Can fish really feel pain? Fish Fisher. 15:97-133.

Rossiter, H.E., Worthen, S.F., Witton, C., Hall, S.D. and Furlong, P.H. (2013). Gamma oscillatory amplitude encodes stimulus intensity in primary somatosensory cortex. Front. Hum. Neurosci. 7:article 362.

Salas, C., Broglio, C., Duran, E., Gomez, A., Ocana, F.M., Jimenez-Moya, F. and Rodriguez, F. (2006). Neuropsychology of learning and memory in teleost fish. Zebrafish 3:157-171.

Salinas, E. and Sejnowski, T.J. (2001). Correlated neuronal activity and the flow of neural information. Nat. Rev. Neurosci. 2:539-550.

Sarvestani, I.K., Kozlov, A., Harischandra, N., Grillner, S. and Ekeberg, O. (2013). A computational model of visually guided locomotion in lamprey. Biol. Cybern. 107:497512.

Sashindranath, M., Daglas, M. and Medcalf, R.L. (2015). Evaluation of gait impairment in mice subjected to craniotomy and traumatic brain injury. Behav. Brain Res. 286:3338.

Schmidt, R., Beil, T., Strähle, U. and Rastegar, S. (2014). Stab wound injury of the zebrafish adult telencephalon: a method to investigate vertebrate brain neurogenesis and regeneration. J. Vis. Exp. 90:e51753.

Schnitzler, A. and Ploner, M. (2000). Neurophysiology and functional neuroanatomy of pain perception. J. Clin. Neurophysiol. 17:592-603.

Schwagmeyer, P., Davis, R.E. and Kassel, J. (1977). Telencephalic lesions and behaviour in the Teleost Macropodus opercularis (L.): effects of telencephalon and olfactory bulb ablation on spawning and foamnest building. Behav. Biol. 20:463-470. 
Scott, T.R. (2014). Insular cortex as a mediator of emotion: commentary on emotion and decision-making explained, by Edmund T. Rolls. Cortex. 59:206-207.

Segerdahl, A.R., Mezue, M., Okell, T.W., Farrar, J.T. and Tracey, I. (2015). The dorsal posterior insula subserves a fundamental role in human pain. Nature Neurosci. 18:499-502.

Selimbeyoglu, A. and Parvizi, J. (2010). Electrical stimulation of the human brain: perceptual and behavioural phenomena reported in the old and new literature. Front. Hum. Neurosci. 4:a46.

Sherrington, C.S. (1910). Flexion-reflex of the limb, crossed extensionreflex, and reflex stepping and standing. J. Physiol. 40:28-121.

Shewmon, D.A., Homles, G.L. and Byrne, P.A. (1999). Consciousness in congenitally decorticate children: development vegetative state as self-fulfilling prophecy. Develop. Med. Child Neurol. 41:364-374.

Short, R.G. and Kardon, A. (2014). 18F-FDG PET/CT in a 16-year-old patient with hydraencephaly. Clin. Nucl. Med. 39:e445-e447.

Silvanto, J. (2014). Is primary visual cortex necessary for visual awareness? Trends Neurosci. 37:618-619.

Silverstein, D.N. (2015). A computational investigation of feedforward and feedback processing in metacontrast backward masking. Front. Psychol. 6:6.

Singer, W. (2011). Dynamic formation of functional networks by synchronization. Neuron. 69:191-193.

Sitt, J.D., King, J.-R., Karoui, I.E., Rohaut, B., Faugeras, F., Gramfort, A., Cohen, L., Sigman, M., Dehaene, S. and Naccache, L. (2014). Large scale screening of neural signatures of consciousness in patients in a vegative or minimally conscious state. Brain. 137:22582270 .

Sporns, 0. (2013). Network attributes for segregation and integration in the human brain. Curr. Opin. Neurobiol. 23:162-171.

Starr, C.J., Sawaki, L., Wittenberg, G.F., Burdette, J.H., Oshiro, Y., Quevedo, A.S. and Coghill, R.C. (2009). Roles of the insular cortex in the modulation of pain: insights from brain lesions. J. Neurosci. 29:2684-2694.

Stephani, C., Fernandez-Baca Vaca, G., Maciunas, R., Koubeissi, M. and Luders, H.O. (2011). Functional nueroanatomy of the insular cortex. Brain Struct. Funct. 216:137-149.

Stoerig, P. (2001). The neuroanatomy of phenomenal vision: a psychological perspective. Ann. N.Y. Acad. Sci. 929:176-194. 
Sussillo, D. (2014). Neural circuits as computational dynamical systems. Curr. Opin. Neurobiol. 25:156-163.

Tacon, A.G.J. and Metian, M. (2013). Fish matters: importance of aquatic foods in human nutrition and global food supply. Rev. Fish Sci. 21:22-38.

Thompson, S.J. and Bushnell, M.C. (2012). Rodent functional and anatomical imaging of pain. Neurosci. Let. 520:131-139.

Tiemann, L., Schulz, E., Gross, J. and Ploner, M. (2010). Gamma oscillations as a neuronal correlate of the attentional effects of pain. Pain. 150:302-308.

Tiesinga, P. and Sejnowski, T.J. (2009). Cortical enlightment: are attentional gamma oscillations driven by ING or PING? Neuron. 63:727-732.

Tracey, I. and Mantyh, P.W. (2007). The cerebral signature for pain perception and its modulation. Neuron. 55:377-391.

Tschopp, P. and Duboule, D. (2011). A genetic approach to the transcriptional regulation of Hox gene clusters. Ann. Rev. Genet. 45:145-166.

Tveteras, S., Asche, F., Bellemare, M.F., Smith, M.D., Guttormsen, A.G., Lem, A., Lien, K. and Vannuccini, S. (2012). Fish is food - the FAO's fish price index. PLoS ONE 7(5): e36731.

Uddin, L.Q. (2015). Salience processing and insular cortical function and dysfunction. Nature Rev. Neurosci. 16:55-61.

Veldhuijzen, D.S., Greenspan, J.D., Kim, J.H. and Lenz, F.A. (2010). Altered pain and thermal sensation in subjects with isolated parietal and insular cortical lesions. Eur. J. Pain. 14:535.e1-11.

Vierck, C.J., Whitsel, B.L., Favorov, O.V., Brown, A.W. and Tommerdahl, M. (2013). Role of primary somatosensory cortex in the coding of pain. Pain. 154:334-344.

Wager, T.D., Atlas, L.Y., Lindquist, M.A., Roy, M., Woo, C-W., and Kross, E. (2013). An fMRIbased neurologic signature of physical pain. N. Engl. J. Med. 368:1388-1397.

Weich, K., Jbabdi, S., Lin, C.S., Andersson, J. and Tracey, I. (2014). Differential structural and resting state connectivity between insular subdivisions and other pain-related brain regions. Pain. 155:2047-2055.

Werth, R. (2007). Residual visual function after loss of both cerebral hemispheres in infancy. Invest. Ophthal. Vis. Sci. 48:3098-3106.

Werth, R. (2008). Cerebral blindness and plasticity of the visual system in children. A review of visual capacities in patients with occipital lesions, hemispherectomy or hydranencephaly. Restor. Neurol. Neurosci. 26:377-389. 
Wessel, K., Vieregge, P., Kessler, C. and Kompf, D. (1994). Thalamic stroke: correlation of clinical symptoms, somatosensory evoked potentials, and CT findings. Acta Neurol. Scand. 90:167-173.

Wolf, F., Engelken, R., Puelma-Touzel, M., Weidinger, J.D.F. and Neef, A. (2014). Dynamical models of cortical circuits. Curr. Opin. Neurobiol. 25:228-236.

Xu, X., Zhou, Z., Dudley, R., Mackem, S., Chuong, C-M., Erickson, G.M. and Varricchio, D.J. (2014). An integrative approach to understanding bird evolution. Science 346:1341.

Yager, D., Sharma, S.C. and Grover, B.G. (1977). Visual function in goldfish with unilateral and bilateral tectal ablation. Brain Res. 137:267-275.

Zhan, X. and Yu, R. (2015). A window into the brain: advances in psychiatric fMRI. Biomed. Res. Internat. 2015:542467.

Zhang, J. (2012). Genetic redundancies and their evolutionary maintenance. Adv. Exper. Med. Biol. 751:279-300.

Zhang, Z.G., Hu, L., Hung, Y.S., Mouraux, A. and Iannetti, G.D. (2012). Gamma-band oscillations in the primary somatosensory cortex - a direct and obligatory correlate of subjective pain intensity. J. Neurosci. 32:7429-7438. 


\section{UQÀM/ISC Cognitive Science Summer School June 26 - July 6 2018, Montreal, Canada}

\section{The Other Minds Problem: Animal Sentience and Cognition}

Overview. Since Descartes, philosophers know there is no way to know for sure what - or whether - others feel (not even if they tell you). Science, however, is not about certainty but about probability and evidence. The 7.5 billion individual members of the human species can tell us what they are feeling. But there are 9 million other species on the planet (20 quintillion individuals), from elephants to jellyfish, with which humans share biological and cognitive ancestry, but not one other species can speak: Which of them can feel — and what do they feel? Their human spokespersons - the comparative psychologists, ethologists, evolutionists, and cognitive neurobiologists who are the world's leading experts in "mindreading" other species -- will provide a sweeping panorama of what it feels like to be an elephant, ape, whale, cow, pig, dog, bat, chicken, fish, lizard, lobster, snail: This growing body of facts about nonhuman sentience has profound implications not only for our understanding of human cognition, but for our treatment of other sentient species.

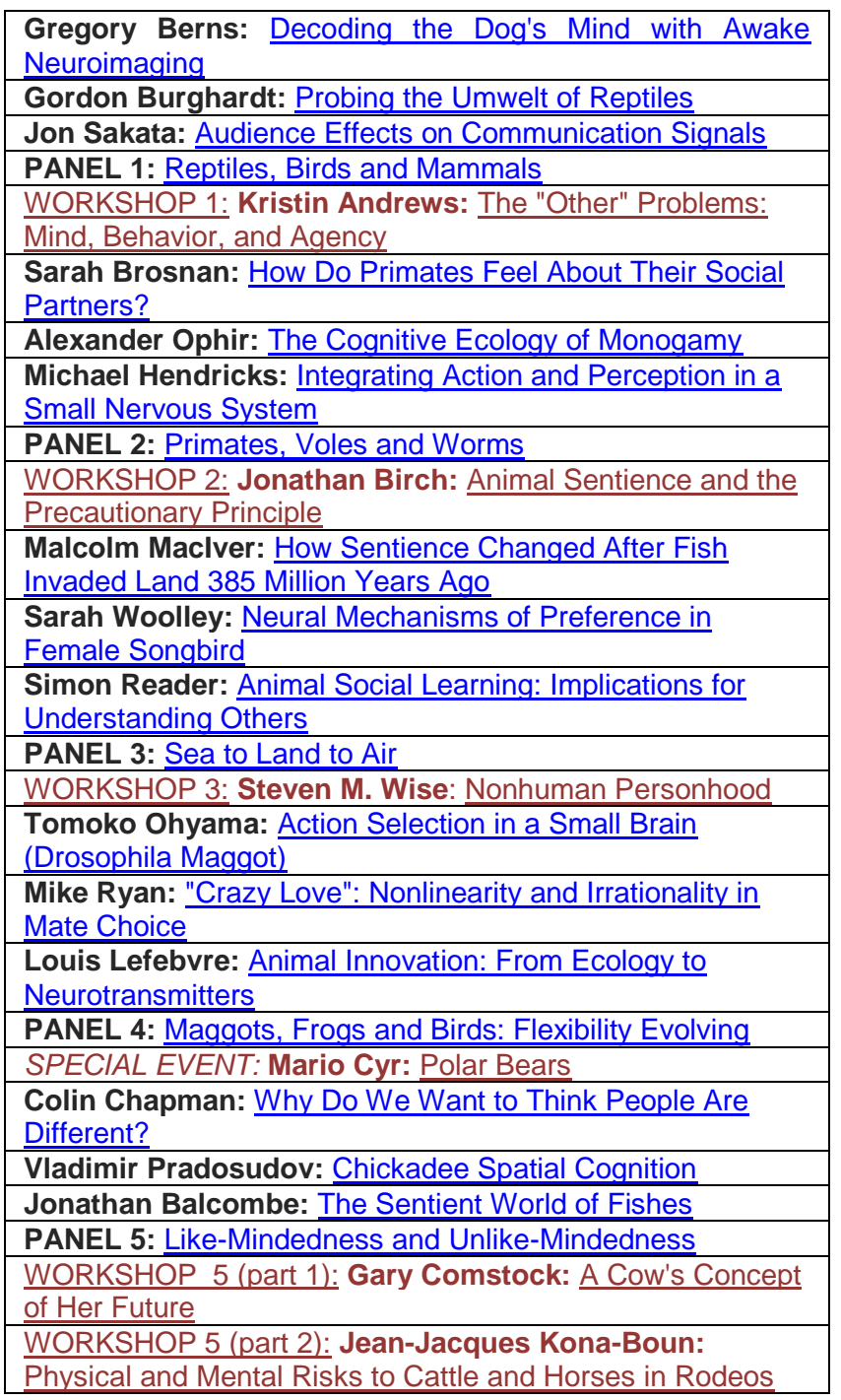

\begin{tabular}{l}
\hline Joshua Plotnik: Thoughtful Trunks: Application of Elephant \\
Cognition for Elephant Conservation \\
\hline Lori Marino: Who Are Dolphins? \\
\hline PANEL 6: Mammals All, Great and Small \\
\hline Larry Young: The Neurobiology of Social Bonding, Empathy \\
and Social Loss in Monogamous Voles \\
\hline WORKSHOP 6: Lori Marino: The Inconvenient Truth About \\
\hline Thinking Chickens \\
\hline Andrew Adamatzky: Slime Mould: Cognition Through \\
Computation \\
\hline Frantisek Baluska \& Stefano Mancuso: What a Plant \\
Knows and Perceives \\
\hline Arthur Reber: A Novel Theory of the Origin of Mind: \\
Conversations With a Caterpillar and a Bacterium \\
\hline PANEL 7: Microbes, Molds and Plants \\
\hline WORKSHOP 7: Suzanne Held \& Michael Mendl: Pig \\
\hline Cognition and Why It Matters \\
\hline James Simmons: What Is It Like To Be A Bat? \\
\hline Debbie Kelly: Spatial Cognition in Food-Storing \\
\hline Steve Phelps: Social Cognition Across Species \\
\hline PANEL 8: Social Space \\
\hline WORKSHOP 8: To be announced \\
\hline Lars Chittka: The Mind of the Bee \\
\hline Reuven Dukas: Insect Emotions: Mechanisms and \\
Evolutionary Biology \\
\hline Adam Shriver: Do Human Lesion Studies Tell Us the Cortex \\
is Required for Pain Experiences? \\
\hline PANEL 9: The Invertebrate Mind \\
\hline WORKSHOP 9: Delcianna Winders: Nonhuman Animals in \\
\hline Sport and Entertainment \\
\hline $\begin{array}{l}\text { Carel ten Cate: } \text { Avian Capacity for Categorization and } \\
\text { Abstraction }\end{array}$ \\
\hline Jennifer Mather: Do Squid Have a Sense of Self? \\
\hline Steve Chang: Neurobiology of Monkeys Thinking About \\
Other Monkeys \\
\hline PANEL 10: Others in Mind \\
\hline WORKSHOP 10: The Legal Status of Sentient Nonhuman \\
\hline Species \\
\hline
\end{tabular}

